University of Nebraska - Lincoln

DigitalCommons@University of Nebraska - Lincoln

\title{
Contributions of Nanoscale Roughness to Anomalous Colloid Retention and Stability Behavior
}

\author{
Scott A. Bradford \\ USDA-ARS, Scott.Bradford@ars.usda.gov \\ Hyunjung Kim \\ Chonbuk National University \\ Chongyang Shen \\ China Agricultural University \\ Salini Sasidharan \\ University of California, Riverside \\ Jianying Shang \\ China Agricultural University
}

Follow this and additional works at: https://digitalcommons.unl.edu/usdaarsfacpub

Bradford, Scott A.; Kim, Hyunjung; Shen, Chongyang; Sasidharan, Salini; and Shang, Jianying, "Contributions of Nanoscale Roughness to Anomalous Colloid Retention and Stability Behavior" (2017). Publications from USDA-ARS / UNL Faculty. 1774.

https://digitalcommons.unl.edu/usdaarsfacpub/1774

This Article is brought to you for free and open access by the U.S. Department of Agriculture: Agricultural Research Service, Lincoln, Nebraska at DigitalCommons@University of Nebraska - Lincoln. It has been accepted for inclusion in Publications from USDA-ARS / UNL Faculty by an authorized administrator of DigitalCommons@University of Nebraska - Lincoln. 


\title{
Contributions of Nanoscale Roughness to Anomalous Colloid Retention and Stability Behavior
}

\author{
Scott A. Bradford, ${ }^{* \dagger} \dagger$ Hyunjung Kim, ${ }^{*}$ Chongyang Shen, ${ }^{\S}$ Salini Sasidharan," and Jianying Shang ${ }^{\S}$ \\ ${ }^{\dagger}$ US Salinity Laboratory, USDA, ARS, Riverside, California 92507, United States \\ ${ }^{\ddagger}$ Department of Mineral Resources and Energy Engineering, Chonbuk National University, 664-14 Duckjin, Jeonju, Jeonbuk 561-756, \\ Republic of Korea \\ ${ }^{\S}$ Department of Soil and Water Sciences, China Agricultural University, Beijing, China 100193 \\ "Department of Environmental Sciences, University of California, Riverside, California 92521, United States
}

\section{Supporting Information}

ABSTRACT: All natural surfaces exhibit nanoscale roughness (NR) and chemical heterogeneity $(\mathrm{CH})$ to some extent. Expressions were developed to determine the mean interaction energy between a colloid and a solid-water interface, as well as for colloid-colloid interactions, when both surfaces contain binary NR and $\mathrm{CH}$. The influence of heterogeneity type, roughness parameters, solution ionic strength (IS), mean zeta potential, and colloid size on predicted interaction energy profiles was then investigated. The role of $\mathrm{CH}$ was enhanced on smooth surfaces with larger amounts of $\mathrm{CH}$, especially for
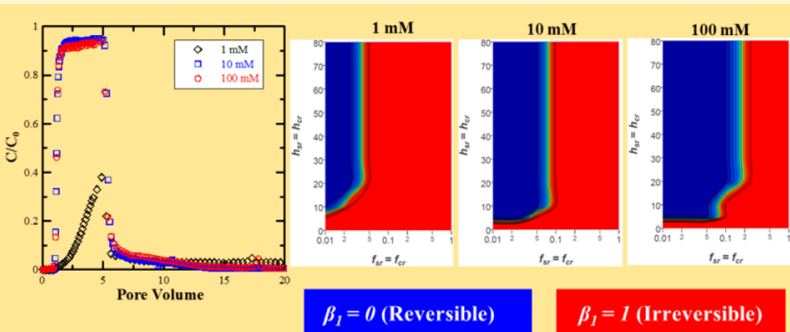
smaller colloids and higher IS. However, predicted interaction energy profiles were mainly dominated by NR, which tended to lower the energy barrier height and the magnitudes of both the secondary and primary minima, especially when the roughness fraction was small. This dramatically increased the relative importance of primary to secondary minima interactions on net electrostatically unfavorable surfaces, especially when roughness occurred on both surfaces and for conditions that produced small energy barriers (e.g., higher IS, lower $\mathrm{pH}$, lower magnitudes in the zeta potential, and for smaller colloid sizes) on smooth surfaces. The combined influence of roughness and Born repulsion frequently produced a shallow primary minimum that was susceptible to diffusive removal by random variations in kinetic energy, even under electrostatically favorable conditions. Calculations using measured zeta potentials and hypothetical roughness properties demonstrated that roughness provided a viable alternative explanation for many experimental deviations that have previously been attributed to electrosteric repulsion (e.g., a decrease in colloid retention with an increase in solution IS; reversible colloid retention under favorable conditions; and diminished colloid retention and enhanced colloid stability due to adsorbed surfactants, polymers, and/or humic materials).

\section{INTRODUCTION}

An understanding of factors that influence interactions of colloids with solid surfaces in the presence of water is needed for many industrial and environmental applications, including: the design of surfaces to enhance or diminish colloid retention, ${ }^{1}$ wastewater treatment, ${ }^{2}$ remediation of hazardous waste sites, ${ }^{3}$ risk assessment of pathogenic microorganisms and engineered nanoparticles, ${ }^{4}$ colloid-facilitated contaminant transport, ${ }^{5}$ petroleum production, ${ }^{6}$ and managed aquifer storage and recovery. ${ }^{7}$ Conventional filtration theory considers that the retention rate coefficient depends on the mass transfer and immobilization of colloids on the solid surface. ${ }^{8}$ Colloid immobilization has commonly been assumed to be controlled by the adhesive interaction between a colloid and a solid-water interface (SWI). ${ }^{8}$ Similarly, the adhesive interaction between colloids determines the stability of a suspension. ${ }^{9}$

The adhesive interaction is commonly derived from interaction energy calculations that consider electrostatic double layer and van der Waals interactions, ${ }^{10,11}$ but may also be extended to include short-range interactions such as Born repulsion, steric, and Lewis acid-base interactions that are still incompletely understood., ${ }^{9,12}$ Colloid and natural surfaces always exhibit some degree of nanoscale roughness (NR) and chemical heterogeneity $(\mathrm{CH}),{ }^{13,14}$ and interaction energy calculations based on homogeneous surfaces have frequently been shown to provide an inadequate description of colloid retention on the SWI or colloid stability. ${ }^{14-16} \mathrm{~A}$ number of researchers have modified interaction energy calculations to account for $\mathrm{NR}$ and/or $\mathrm{CH}$ on surfaces in order to overcome these limitations. ${ }^{14-22}$ For example, the surface element integration approach allows for the consideration of NR and/ or $\mathrm{CH}$ on the SWI or the colloid. ${ }^{16}$ Results have demonstrated that the mean interaction energy on a heterogeneous surface can be represented as a linear expression of interactions

Received: July 14, 2017

Revised: August 23, 2017

Published: August 28, 2017 
energies associated with the various heterogeneity combinations within the electrostatic zone of influence. ${ }^{15,16,22}$ For example, Bradford and Torkzaban ${ }^{22}$ demonstrated that the influence of binary NR and $\mathrm{CH}$ on the SWI could be accurately accounted for using a linear expression of the various interaction energies.

Nanoscale heterogeneities have been shown to have a large influence on predicted interaction energy profiles. ${ }^{14-23}$ In brief, electrostatically unfavorable surfaces can exhibit localized reductions and/or elimination of the energy barrier due to the presence of nanoscale heterogeneity in zeta potential, depending on the amount, size, and charge of the $\mathrm{CH}$ within the electrostatic zone of influence, the solution ionic strength (IS), and the colloid size. ${ }^{16,23}$ In general, the influence of a given $\mathrm{CH}$ increases at higher IS and for smaller colloid size. ${ }^{23}$ The energy barrier on electrostatically unfavorable surfaces can also be locally reduced or eliminated by $\mathrm{NR}^{14-22}$ In addition, the depths of the secondary and primary minima can also be reduced by NR depending on the amount, size, and height of the NR within the electrostatic zone of influence. ${ }^{22}$ Some interacting colloids are therefore susceptible to diffusive and/or hydrodynamic removal on rough surfaces, ${ }^{24}$ even under electrostatically favorable conditions. ${ }^{25}$ When both NR and $\mathrm{CH}$ are considered on the SWI, results indicate that NR tends to control the interaction energy profile shape, as well as colloid retention and release. ${ }^{16,22,24}$

To date, no published studies have considered the influence of NR and $\mathrm{CH}$ on both the SWI and the colloid. Consequently, it is presently unclear whether heterogeneity needs to be considered only on the SWI, only on the colloid, or on both the SWI and colloid. Furthermore, the predicted influence of NR on interaction energy profiles depends not only on roughness parameters, but also on parameters that influence electrostatic and van der Waals interactions. ${ }^{16,22}$ However, the coupled influence of NR and interaction energy (e.g., zeta potentials, solution chemistry, and colloid size) parameters has not yet been systematically studied when heterogeneity occurs on both the colloid and the SWI. Consideration of these effects may provide a viable alternative explanation for experimental observations that have typically been attributed to electrosteric repulsion. $^{26-32}$ For example, electrosteric repulsion has been invoked to explain: (i) a decrease in colloid retention with an increase in solution $\mathrm{IS}^{26,27}$ (ii) reversible colloid retention under favorable conditions; ${ }^{28,29}$ (iii) diminished colloid retention due to adsorbed humic materials; ${ }^{30}$ and (iv) enhance stability of colloid suspensions by adsorbed polymers and surfactants. ${ }^{31,32}$ However, this literature has not explicitly considered the role of NR on the SWI or the colloid in their interaction energy calculations.

In this work we present simple linear expressions to determine the mean interaction energy between a colloid and a SWI, as well as for colloid-colloid interactions, when both surfaces contain binary $\mathrm{NR}$ and $\mathrm{CH}$. Next, we investigate the relative importance of $\mathrm{NR}$ and $\mathrm{CH}$ on predicted interaction energy profiles. We then systematically study the coupled role of NR on the colloid and SWI with various interaction energy parameters in order to test the hypothesis that it can explain many experimental deviations that have previously been attributed to electrosteric repulsion. Results from this research provide valuable insight on: (i) the relative importance of various nanoscale heterogeneity types on interaction energies; (ii) the influence of NR with various interaction energy parameters; and (iii) a viable alternative explanation for experimental deviations that have previously been attributed to electrosteric repulsion. Furthermore, this approach can be used to design surfaces with enhanced or diminished colloid interactions by selecting the optimum $\mathrm{NR}$ and $\mathrm{CH}$ parameters.

\section{MATERIALS AND METHODS}

Interaction Energies. In this research, we assume that a spherical colloid is suspended in a monovalent electrolyte solution with a given IS and interacts with the surface of a porous medium. Both interacting surfaces may exhibit binary $\mathrm{NR}$ and $\mathrm{CH}$ within the area of the electrostatic zone of influence $\left(A_{z}, \mathrm{~L}^{2}\right.$ where $\mathrm{L}$ denotes units of length). The value of $A_{z}$ refers to the projected area of the colloid on the SWI that effectively contributes to the colloid-SWI interaction energy and is proportional to the colloid radius and the Debye length. ${ }^{33}$ Symmetry implies that the same value of $A_{z}$ also acts on the colloid. This assumption (i.e., pairwise interaction) is also invoked in commonly employed Derjaguin and surface element integration methods. ${ }^{3,35}$ Figure 1 provides a schematic illustrating NR and $\mathrm{CH}$

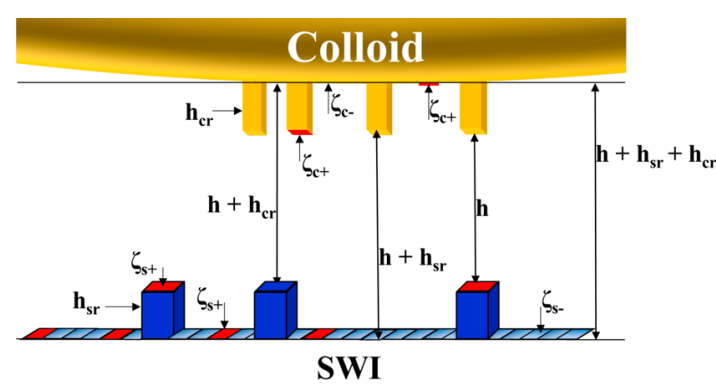

Figure 1. Schematic illustrating NR and $\mathrm{CH}$ on the colloid and SWI within the electrostatic zone of influence. Here $h_{\mathrm{sr}}$ and $h_{\mathrm{cr}}$ is the height of the roughness on the SWI and colloid, respectively, and $h$ is the separation distance from $h_{\mathrm{cr}}$ on the colloid to $h_{\mathrm{sr}}$ on the SWI. The red color represents positive zeta potentials on the colloid $\left(\zeta_{\mathrm{ct}}\right)$ and SWI $\left(\zeta_{s+}\right)$, whereas nonred surfaces are negatively charged $\left(\zeta_{c-}\right.$ for the colloid, and $\zeta_{\mathrm{s}-}$ for the SWI).

on the colloid and SWI within $A_{z}$. Note that $A_{z}$ on the SWI contains a NR fraction $\left(f_{\mathrm{sr}}\right)$ with a height equal to $\mathrm{h}_{\mathrm{sr}}$ and a positive zeta potential fraction $\left(f_{s+}\right)$ that is equal to $\zeta_{s+}$. The complementary fractions $(1-$ $\left.f_{\mathrm{sr}}\right)$ and $\left(1-f_{\mathrm{s}+}\right)$ correspond to a smooth surface and a negative zeta potential $\zeta_{s-}$, respectively. Similar $\mathrm{NR}$ and $\mathrm{CH}$ parameters were defined within $A_{z}$ for the colloid as for the SWI. In this case, parameters $f_{\mathrm{sr}}, f_{\mathrm{s}+}, h_{\mathrm{sr}}, \zeta_{\mathrm{s}+}$, and $\zeta_{\mathrm{s}-}$ for the SWI correspond to $f_{\mathrm{cr}}, f_{\mathrm{c}+}, h_{\mathrm{cr}}$, $\zeta_{c^{+}+}$and $\zeta_{c-}$ for the colloid, respectively.

It has previously been demonstrated that the mean value of the dimensionless (divided by the product of the Boltzmann constant and absolute temperature) interaction energy $(\Phi)$, from many realizations of the same heterogeneity parameters, can be determined as a linear combination of interaction energies associated with the $\mathrm{NR}$ and $\mathrm{CH}$ fractions within $A_{z} \cdot{ }^{15,16,22}$ This approach is extended in this research to account for binary NR and $\mathrm{CH}$ on both the SWI and colloid as

$$
\begin{aligned}
\Phi(h)= & a_{\mathrm{r} 1} \Phi_{\mathrm{s}}\left(h+h_{\mathrm{sr}}+h_{\mathrm{cr}}\right)+a_{\mathrm{r} 2} \Phi_{\mathrm{s}}\left(h+h_{\mathrm{sr}}\right)+a_{\mathrm{r} 3} \Phi_{\mathrm{s}}\left(h+h_{\mathrm{cr}}\right) \\
& +a_{\mathrm{r} 4} \Phi_{\mathrm{s}}(h)
\end{aligned}
$$

where $h[\mathrm{~L}]$ is the separation distance from the center of $A_{z}$ at a height $h_{\mathrm{sr}}$ from the SWI to the leading face of the colloid center at a height $h_{\mathrm{cr}}$ (see Figure 1), $\Phi_{s}$ is the dimensionless interaction energy associated with a smooth, nanoscale chemically heterogeneous surface, and $a_{\mathrm{r} 1}$ $[-], a_{\mathrm{r} 2}[-], a_{\mathrm{r} 3}[-]$, and $a_{\mathrm{r} 4}[-]$ are constants that determine the contributions of the various possible roughness combinations (e.g., smooth SWI and smooth colloid, smooth SWI and rough colloid, rough SWI and smooth colloid, and rough SWI and rough colloid, respectively) that are equal to 


$$
\begin{aligned}
& a_{\mathrm{r} 1}=\left(1-f_{\mathrm{sr}}\right)\left(1-f_{\mathrm{cr}}\right) \\
& a_{\mathrm{r} 2}=\left(1-f_{\mathrm{sr}}\right) f_{\mathrm{cr}} \\
& a_{\mathrm{r} 3}=f_{\mathrm{sr}}\left(1-f_{\mathrm{cr}}\right) \\
& a_{\mathrm{r} 4}=f_{\mathrm{sr}} f_{\mathrm{cr}}
\end{aligned}
$$

The value of $\Phi_{s}$ is given as ${ }^{23}$

$$
\begin{aligned}
\Phi_{\mathrm{s}}(h)= & a_{\mathrm{c} 1} \Phi_{\mathrm{s}-\mathrm{c}-}(h)+a_{\mathrm{c} 2} \Phi_{\mathrm{s}-\mathrm{c}+}(h)+a_{\mathrm{c} 3} \Phi_{\mathrm{s}+\mathrm{c}-}(h) \\
& +a_{\mathrm{c} 4} \Phi_{\mathrm{s}+\mathrm{c}+}(h)
\end{aligned}
$$

where $\Phi_{s-c-1} \Phi_{s-c+,} \Phi_{s+c-\text {, }}$ and $\Phi_{s+c+}$ are dimensionless interaction energies that determine the contributions of the possible $\mathrm{CH}$ combinations (e.g., solid and colloid zeta potentials of $\zeta_{s-}$ and $\zeta_{c-}$; $\zeta_{s-}$ and $\zeta_{\mathrm{c}+} ; \zeta_{\mathrm{s}+}$ and $\zeta_{\mathrm{c}-}$; and $\zeta_{\mathrm{s}+}$ and $\zeta_{\mathrm{c}+}$, respectively), and $a_{\mathrm{c} 1}[-], a_{\mathrm{c} 2}$ $[-], a_{\mathrm{c} 3}[-]$, and $a_{\mathrm{c} 4}[-]$ are constants that are equal to

$$
\begin{aligned}
& a_{\mathrm{c} 1}=\left(1-f_{\mathrm{s}+}\right)\left(1-f_{\mathrm{c}+}\right) \\
& a_{\mathrm{c} 2}=\left(1-f_{\mathrm{s}+}\right) f_{\mathrm{c}+} \\
& a_{\mathrm{c} 3}=f_{\mathrm{s}+}\left(1-f_{\mathrm{c}+}\right) \\
& a_{\mathrm{c} 4}=f_{\mathrm{s}+} f_{\mathrm{c}+}
\end{aligned}
$$

Equationss 1-4 were also applied for colloid-colloid interactions. All of the above interaction energies considered electrostatics, ${ }^{36}$ retarded London-van der Waals attraction, ${ }^{37}$ and Born repulsion ${ }^{38,39}$ that are summarized in section S1 of the Supporting Information for sphereplate and sphere-sphere geometries. It should be mentioned that eqs 1-4 assumed that $h>0$ such that roughness on the colloid and SWI (or colloid) do not overlap (Figure 1). Furthermore, lateral interactions between NR on the colloid and the SWI (or colloid) were assumed to be distributed (e.g., randomly or exhibited symmetry) such that their average contribution to the interaction energy cancels out.

Equations 1-4 therefore allow the influence of $\mathrm{NR}$ and $\mathrm{CH}$ to be systematically investigated for various heterogeneity combinations. In this work, the following heterogeneity combinations were considered: physically and chemically homogeneous characteristics on both the SWI and colloid (denoted as H-Both); NR on the SWI (denoted as NR-SWI); NR on the colloid (denoted as NR-Colloid); NR on both the SWI and colloid (NR-Both); CH on both the SWI and colloid (CH-Both); and $\mathrm{CH}$ and NR on both the colloid and SWI (CH+NRBoth). All interaction energy profiles were analyzed to determine the energy barrier height $\left(\Phi_{\max }\right)$, and the depths of the secondary $\left(\Phi_{2 \min }\right)$ and primary $\left(\Phi_{1 \min }\right)$ minima.

Energy Balance. The kinetic energy model was used to determine the probability that a colloid interacting in a primary or secondary minimum would be immobilized in the presence of random kinetic energy fluctuations of a diffusing colloid. In this case, the immobilization probability $\left(\varepsilon_{j}\right)$ was determined by using the Maxwellian cumulative density function to account for the kinetic energy distribution of a diffusing colloid and evaluating it over specific ranges in the interaction energy profile: ${ }^{24,40,41}$

$$
\begin{aligned}
\varepsilon_{j}= & \int_{A}^{B} \frac{2 \sqrt{\Phi}}{\sqrt{\pi}} \exp (-\Phi) \mathrm{d} \Phi \\
= & \left(\operatorname{erf}(\sqrt{B})-\sqrt{\frac{4 B}{\pi}} \exp (-B)\right) \\
& -\left(\operatorname{erf}(\sqrt{A})-\sqrt{\frac{4 A}{\pi}} \exp (-A)\right)
\end{aligned}
$$

where $A$ is the lower integration limit, $B$ is the upper integration limit, and the subscript $j$ on $\varepsilon$ indicates whether the immobilization was associated with a primary or secondary minimum $(j=1$ or 2$)$. Values of $A$ and $B$ are equal to the interaction energies to enter and escape from a minimum, respectively. ${ }^{24}$ Equation 5 was also used to determine the probability that interacting colloids would be released from secondary and primary minima $\left(\varepsilon_{\mathrm{r} 1}\right.$ and $\left.\varepsilon_{\mathrm{r} 2}\right)$ by diffusion. In this case, $A$ is equal to the minimum kinetic energy to escape from the minimum and $B=\infty$ (e.g., the maximum kinetic energy). ${ }^{24}$

Figure S1 presents a plot of $\varepsilon_{1}$ as a function of $\Phi_{\max }$ when $\Phi_{2 \min }=0$ and $\Phi_{1 \min }=-\infty$ (unfavorable electrostatic conditions), and $\varepsilon_{r 1}$ as a function of $\Phi_{1 \min }$ when $\Phi_{2 \min }=0$ and $\Phi_{\max }=0$ (favorable electrostatic conditions). Note that $\varepsilon_{1}$ rapidly increases with decreasing $\Phi_{\max }$ when $\Phi_{\max }<5.6$, and $\varepsilon_{\mathrm{r} 1}$ similarly increases with increasing $\Phi_{1 \min }$ when $\Phi_{1 \min }>-5.6$. Consequently, long-term colloid immobilization in a primary minimum is only possible when $\Phi_{\max }<5.6$ and $\Phi_{1 \min }<-5.6$. Long-term colloid immobilization in a secondary minimum is only possible when $\Phi_{2 \min }<-5.6$ for a similar reason. These criteria for long-term colloid immobilization are expressed mathematically using $\beta_{j}$ terms that are given as ${ }^{24}$

$$
\beta_{j}=H_{\mathrm{o}}\left(\varepsilon_{j}-\varepsilon_{\mathrm{c}}\right) H_{\mathrm{o}}\left(\varepsilon_{\mathrm{c}}-\varepsilon_{\mathrm{r} j}\right)
$$

where $\varepsilon_{\mathrm{c}}$ is a critical threshold for long-term colloid immobilization and $H_{\mathrm{o}}$ is a Heaviside function. The value of $H_{\mathrm{o}}=1$ when the quantity in parentheses is greater than or equal to 0 , and $H_{\mathrm{o}}=0$ when this quantity is less than 0 . In this work we have selected $\varepsilon_{c}=0.01$ to correspond to a magnitude of an interaction energy to enter and escape from a minimum of less than 5.6 (cf., Figure S1). A value of $\varepsilon_{j}>$ 0 and $\beta_{j}=0$ indicates reversible retention, whereas $\varepsilon_{j}>0$ and $\beta_{j}=1$ denotes irreversible retention for a given solution chemistry condition. It should be mentioned that eqs 5 and 6 only consider the influence of adhesion and diffusion on colloid immobilization. The role of hydrodynamics on colloid immobilization and the heterogeneous spatial distributions of $\mathrm{NR}$ and $\mathrm{CH}$ parameters may also be incorporated in this framework, ${ }^{24}$ but was not the focus of this study.

Numerical Experiments. Numerical experiments were conducted to explore the influence of $\mathrm{NR}$ and $\mathrm{CH}$ parameters, colloid size, and solution IS on interaction energy profile properties $\left(\Phi_{2 \min }, \Phi_{\max }\right.$ and $\left.\Phi_{1 \min }\right)$ and probabilities for immobilization $\left(\varepsilon_{1}\right.$ and $\left.\varepsilon_{2}\right)$, release $\left(\varepsilon_{\mathrm{r} 1}\right.$ and $\left.\varepsilon_{\mathrm{r} 2}\right)$, and long-term immobilization $\left(\beta_{1}\right.$ and $\left.\beta_{2}\right)$. Two important microbial pathogens were considered in these calculations, namely, Cryptosporidium oocysts ${ }^{28}$ and E. coli O157:H7. ${ }^{26}$ Oocysts are approximately spherical, with a diameter that ranges between 3000 and $6000 \mathrm{~nm} \cdot{ }^{28}$ A sphere-plate interaction was considered between a $4300 \mathrm{~nm}$ oocyst and ultrapure quartz sand. E. coli O157:H7 is a rod shaped Gram-negative bacterium, and the interaction energy will therefore also depend on the orientation of cell with the SWI. ${ }^{42,43}$ However, available research indicates that a sphere-plate geometry may be used to approximate the interaction between E. coli $\mathrm{O} 157: \mathrm{H} 7$ and ultrapure quartz when using an effective cell radius of $720 \mathrm{~nm} .{ }^{42,44}$ Hypothetical biocolloids of 100, 1000, and $5000 \mathrm{~nm}$ diameters were also employed to study the influence of colloid size. A Hamaker constant of $6.5 \times 10^{-21} \mathrm{~J}$ was employed to be consistent with reported values for biocolloids. ${ }^{29}$ The collision diameter was set equal to 0.26 $\mathrm{nm}$ in order to achieve a primary minimum depth at $0.157 \mathrm{~nm}$, a commonly accepted distance of closest approach. ${ }^{45}$ Zeta potentials for oocysts, cells, and ultrapure quartz sand at selected solution chemistry conditions were taken directly from the literature, ${ }^{26,28}$ whereas the zeta potential values for the hypothetical biocolloids were assumed to be the same as oocysts or set to $-10 \mathrm{mV}$.

A wide range of hypothetical NR parameters on the SWI and colloids were considered in numerical experiments to be consistent with expected variability on natural surfaces. For example, Han et al. ${ }^{46}$ measured the roughness of ultrapure quartz sand using atomic force microscopy, and reported a root-mean-square value of $h_{\mathrm{sr}}=33 \mathrm{~nm}$. This value was quite similar to the value of $h_{\mathrm{sr}}=38 \mathrm{~nm}$ that was reported by Rasmuson et al. ${ }^{47}$ for a glass microscope slide that was cleaned with sodium hydroxide. These authors also reported that the maximum valley depths and peak roughness heights were approximately a factor of 5 times the root-mean-square roughness. Atomic force microscope measurements of the oocyst surface indicates the presence of largest asperities are on the order of $250 \mathrm{~nm}$ in diameter and up to approximately $55 \mathrm{~nm}$ high. ${ }^{48-50}$ The root-mean-square roughness over micrometer-sized areas on oocysts was found to be in the range from 5 to $20 \mathrm{~nm}$. Imaging of various bacteria species using 
Table 1. Summary of Experimental Conditions and NR and $\mathrm{CH}$ Parameters for the Numerical Experiments

\begin{tabular}{|c|c|c|c|c|c|c|c|c|c|c|c|c|c|}
\hline Figure & model & $d_{\mathrm{c}}[\mathrm{nm}]$ & IS $[\mathrm{mM}]$ & $\zeta_{s-}[\mathrm{mV}]$ & $\zeta_{c-}[\mathrm{mV}]$ & $\zeta_{s+}[\mathrm{mV}]$ & $f_{s+}[-]$ & $\zeta_{\mathrm{c}+}[\mathrm{mV}]$ & $f_{c+}[-]$ & $h_{\mathrm{sr}}[\mathrm{nm}]$ & $f_{\mathrm{sr}}[-]$ & $h_{\mathrm{cr}}[\mathrm{nm}]$ & $f_{\text {cr }}[-]$ \\
\hline 2 & $a$ & 4300 & 10 & -61.8 & -6.0 & 0.0 & 0.0 & 0.0 & 0.0 & 0.0 & 0.0 & 0.0 & 0.0 \\
\hline 2 & $b$ & 4300 & 10 & -61.8 & -6.0 & 10.0 & 0.025 & 10.0 & 0.025 & 0.0 & 0.0 & 0.0 & 0.0 \\
\hline 2 & ${ }^{c}$ & 4300 & 10 & -61.8 & -6.0 & 0.0 & 0.0 & 0.0 & 0.0 & 25.0 & 0.05 & 0.0 & 0.0 \\
\hline 2 & $d$ & 4300 & 10 & -61.8 & -6.0 & 0.0 & 0.0 & 0.0 & 0.0 & 0.0 & 0.0 & 25.0 & 0.05 \\
\hline 2 & $e$ & 4300 & 10 & -61.8 & -6.0 & 0.0 & 0.0 & 0.0 & 0.0 & 12.5 & 0.025 & 12.5 & 0.025 \\
\hline 2 & $f$ & 4300 & 10 & -61.8 & -6.0 & 10.0 & 0.025 & 10.0 & 0.025 & 12.5 & 0.025 & 12.5 & 0.025 \\
\hline $3 \mathrm{~A}$ & $b$ & 4300 & 10 & -61.8 & -6.0 & 10.0 & 0 & 10.0 & 0.025 & 0.0 & 0.0 & 0.0 & 0.0 \\
\hline $3 \mathrm{~A}$ & $b$ & 4300 & 10 & -61.8 & -6.0 & 10.0 & 0.25 & 10.0 & 0.025 & 0.0 & 0.0 & 0.0 & 0.0 \\
\hline $3 \mathrm{~A}$ & $b$ & 4300 & 10 & -61.8 & -6.0 & 10.0 & 0.50 & 10.0 & 0.025 & 0.0 & 0.0 & 0.0 & 0.0 \\
\hline $3 \mathrm{~A}$ & $b$ & 4300 & 10 & -61.8 & -6.0 & 10.0 & 0.75 & 10.0 & 0.025 & 0.0 & 0.0 & 0.0 & 0.0 \\
\hline $3 \mathrm{~A}$ & $b$ & 4300 & 10 & -61.8 & -6.0 & 10.0 & 1.0 & 10.0 & 0.025 & 0.0 & 0.0 & 0.0 & 0.0 \\
\hline $3 B$ & $f$ & 4300 & 10 & -61.8 & -6.0 & 10.0 & 0 & 10.0 & 0.025 & 12.5 & 0.025 & 12.5 & 0.025 \\
\hline $3 B$ & $f$ & 4300 & 10 & -61.8 & -6.0 & 10.0 & 0.25 & 10.0 & 0.025 & 12.5 & 0.025 & 12.5 & 0.025 \\
\hline $3 B$ & $f$ & 4300 & 10 & -61.8 & -6.0 & 10.0 & 0.50 & 10.0 & 0.025 & 12.5 & 0.025 & 12.5 & 0.025 \\
\hline $3 B$ & $f$ & 4300 & 10 & -61.8 & -6.0 & 10.0 & 0.75 & 10.0 & 0.025 & 12.5 & 0.025 & 12.5 & 0.025 \\
\hline $3 B$ & $f$ & 4300 & 10 & -61.8 & -6.0 & 10.0 & 1.0 & 10.0 & 0.025 & 12.5 & 0.025 & 12.5 & 0.025 \\
\hline 4,5 & $f$ & 4300 & 10 & -61.8 & -6.0 & 10.0 & 0.025 & 10.0 & 0.025 & $h$ & ${ }^{i}$ & $h$ & $i$ \\
\hline 6 & $f$ & 100 & 10 & -61.8 & -6.0 & 10.0 & 0.025 & 10.0 & 0.025 & $h$ & ${ }^{i}$ & $h$ & ${ }^{i}$ \\
\hline $7 \mathrm{~A}$ & $e$ & 4300 & 1 & -66.8 & -5.9 & 0.0 & 0.0 & 0.0 & 0.0 & $h$ & ${ }^{i}$ & $h$ & $i$ \\
\hline $7 \mathrm{~B}$ & $e$ & 4300 & 10 & -61.8 & -6.0 & 0.0 & 0.0 & 0.0 & 0.0 & $h$ & $i$ & $h$ & $i$ \\
\hline $7 \mathrm{C}$ & e & 4300 & 100 & -17.3 & -6.6 & 0.0 & 0.0 & 0.0 & 0.0 & $h$ & ${ }^{i}$ & $h$ & ${ }^{i}$ \\
\hline $8 \mathrm{~A}$ & $e$ & 720 & 1 & -63.8 & -2.1 & 0.0 & 0.0 & 0.0 & 0.0 & $h$ & $i$ & $h$ & $i$ \\
\hline $8 B$ & $e$ & 720 & 10 & -53.5 & -2.1 & 0.0 & 0.0 & 0.0 & 0.0 & $h$ & $i$ & $h$ & $i$ \\
\hline $8 \mathrm{C}$ & $e$ & 720 & 100 & -29.8 & -5.9 & 0.0 & 0.0 & 0.0 & 0.0 & $h$ & ${ }^{i}$ & $h$ & $i$ \\
\hline $9 \mathrm{~A}$ & $g$ & 100 & 100 & -10.0 & -10.0 & 0.0 & 0.0 & 0.0 & 0.0 & $h$ & ${ }^{i}$ & $h$ & ${ }^{i}$ \\
\hline $9 B$ & $g$ & 1000 & 100 & -10.0 & -10.0 & 0.0 & 0.0 & 0.0 & 0.0 & $h$ & ${ }^{i}$ & $h$ & $i$ \\
\hline $9 \mathrm{C}$ & $g$ & 5000 & 100 & -10.0 & -10.0 & 0.0 & 0.0 & 0.0 & 0.0 & $h$ & $i$ & $h$ & $i$ \\
\hline
\end{tabular}

${ }^{a}$ Denotes H-Both with sphere-plate interaction. ${ }^{b}$ Denotes CH-Both with sphere-plate interaction. ${ }^{c}$ Denotes NR-SWI with sphere-plate interaction. ${ }^{d}$ Denotes NR-Colloid with sphere-plate interaction. ${ }^{e}$ Denotes NR-Both with sphere-plate interaction. ${ }^{f}$ Denotes CH+NR-Both with sphere-plate interaction. ${ }^{g}$ Denotes NR-Both with sphere-sphere interaction. ${ }^{h}$ Denotes $h_{\mathrm{sr}}=h_{\mathrm{cr}}$ and values were varied from 0 to $80 \mathrm{~nm} .{ }^{i}$ Denotes $f_{\text {sr }}=f_{\text {cr }}$ and values were varied from 0.01 to 1 .

tunneling electron microscopy has revealed that their macromolecules extend between 5 and $100 \mathrm{~nm}$ into solution. ${ }^{27}$

Charge heterogeneity on the surfaces on the SWI and/or colloids can occur for a variety of reasons, including: protonation of surfaces; charge neutralization or reversal due to the adsorption of multivalent cations; positively charged functional groups on biocolloids; and adsorption of metal oxides and clays on the SWI. ${ }^{13,51,52}$ The $\mathrm{CH}$ parameters were selected to achieve electrostatically favorable conditions, and a wide range of fractions on the SWI.

Table 1 summarizes the experimental conditions and NR $\left(f_{\mathrm{sr}}, h_{\mathrm{sr}}, f_{\mathrm{cr}}\right.$, and $\left.h_{\mathrm{cr}}\right)$ and $\mathrm{CH}\left(f_{\mathrm{s}+}, \zeta_{\mathrm{s}+}, f_{\mathrm{c}+}\right.$, and $\left.\zeta_{\mathrm{c}+}\right)$ parameters used in interaction energy calculations. Roughness parameters on the colloid and SWI were chosen to be the same (e.g., $f_{\mathrm{sr}}=f_{\mathrm{cr}}$ and $h_{\mathrm{sr}}=h_{\mathrm{cr}}$ ) in NR-Both and $\mathrm{CH}+\mathrm{NR}-\mathrm{Both}$ calculations in order to minimize the number of considered roughness parameters. Justification for this choice will be given below.

\section{RESULTS AND DISCUSSION}

Figure 2 presents the interaction energy profile between an oocyst and quartz sand for various $\mathrm{NR}$ and $\mathrm{CH}$ conditions when the IS $=10 \mathrm{mM} \mathrm{NaCl}$. Net electrostatically unfavorable conditions exist in this case $\left(\zeta_{s_{-}}=-61.7 \mathrm{mV}\right.$ and $\zeta_{c_{-}}=-6$ $\mathrm{mV})$. Large values of $\Phi_{2 \min }=-5.2, \Phi_{\max }=101.4$, and $\Phi_{1 \min }=$ -8994.0 therefore occurred in the H-Both calculations, so that oocyst immobilization exclusively occurred in a secondary minimum $\left(\varepsilon_{1}=0\right.$ and $\left.\varepsilon_{2}=0.98\right)$. In comparison to H-Both, CH-Both $\left(f_{\mathrm{s}+}=0.025, \zeta_{\mathrm{s}+}=10 \mathrm{mV}, f_{\mathrm{c}+}=0.025\right.$, and $\zeta_{\mathrm{c}+}=10$ $\mathrm{mV}$ ) lowers $\Phi_{\max }$ to 79.3 , but did not alter $\Phi_{2 \min }=-5.3$ and $\Phi_{1 \text { min }}=-9046.7$ very much so that the secondary minimum continued to dominate immobilization. Inclusion of NR on the

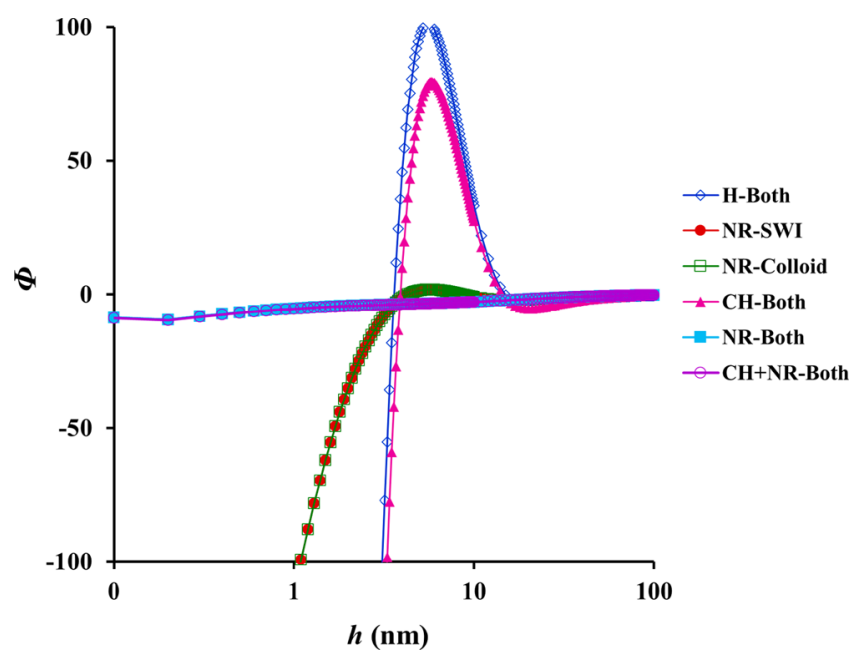

Figure 2. Dimensionless interaction energy profiles between an oocyst and quartz sand for the indicated $\mathrm{NR}$ and $\mathrm{CH}$ conditions when the IS $=10 \mathrm{mM} \mathrm{NaCl}$. Parameter values are summarized in Table 1 .

SWI $\left(f_{\mathrm{sr}}=0.05\right.$ and $\left.h_{\mathrm{sr}}=25 \mathrm{~nm}\right)$ or the colloid $\left(f_{\mathrm{cr}}=0.05\right.$ and $\left.h_{\mathrm{cr}}=25 \mathrm{~nm}\right)$ produced identical interaction energy profiles, with $\Phi_{2 \min }=-2.06, \Phi_{\max }=1.82$, and $\Phi_{1 \min }=-454$. This observation indicates that changes in $h_{\mathrm{sr}}$ or $h_{\mathrm{cr}}$ produced a similar influence on the interaction energy profile. Comparison of interaction energy profiles for H-Both, NR-SWI, and NRColloid indicates that NR significantly decreased the 
magnitudes of $\Phi_{2 \min }, \Phi_{\max }$ and $\Phi_{1 \min }$ such that the relative importance of the secondary minimum was decreased $\left(\varepsilon_{2}\right.$ from 0.98 to 0.75 ) and the primary minimum increased ( $\varepsilon_{1}$ from 0 to $0.05)$. These results are consistent with previous literature findings. ${ }^{14-22}$ Interestingly, consideration of NR on both the oocyst and SWI $\left(f_{\mathrm{sr}}=0.025, h_{\mathrm{sr}}=12.5 \mathrm{~nm}, f_{\mathrm{cr}}=0.025\right.$, and $h_{\mathrm{cr}}=$ $12.5 \mathrm{~nm}$ ) altogether eliminated $\Phi_{2 \min }$ and $\Phi_{\text {max }}$, and produced a relatively shallow $\Phi_{1 \min }=-9.5$. In this case, immobilization was exclusively controlled by the primary minimum and the values of $\varepsilon_{1}=1.0$ and $\varepsilon_{2}=0.0$. The value of $\Phi_{\max }$ was lowered, the magnitude of $\Phi_{1 \text { min }}$ decreased, and therefore $\varepsilon_{1}$ increased for NR-Both $\left(f_{\mathrm{sr}}=f_{\mathrm{cr}}=0.025\right)$ compared to NR-Colloid $\left(f_{\mathrm{sr}}=0\right.$ and $\left.f_{\mathrm{cr}}=0.05\right)$ and NR-SWI $\left(f_{\mathrm{sr}}=0.05\right.$ and $\left.f_{\mathrm{cr}}=0\right)$ due to differences in $f_{\text {sr }}$ and $f_{\text {cr. }}$. Results from the NR-Both and $\mathrm{CH}$ +NR-Both conditions were nearly identical, and this indicates that NR controlled the properties of these interaction energy profiles for the considered heterogeneity parameters. Previous literature ${ }^{14-23}$ has not considered the influence of NR on both the SWI and the colloids, and these calculations clearly demonstrate that inclusion of NR on both the SWI and the colloid has a large influence on the interaction energy profile and the probability for immobilization under electrostatically unfavorable conditions.

Additional interaction energy calculations were conducted to better elucidate the relative importance of $\mathrm{CH}$ and $\mathrm{NR}$ over a wider range of conditions. Figure 3 presents interaction energy
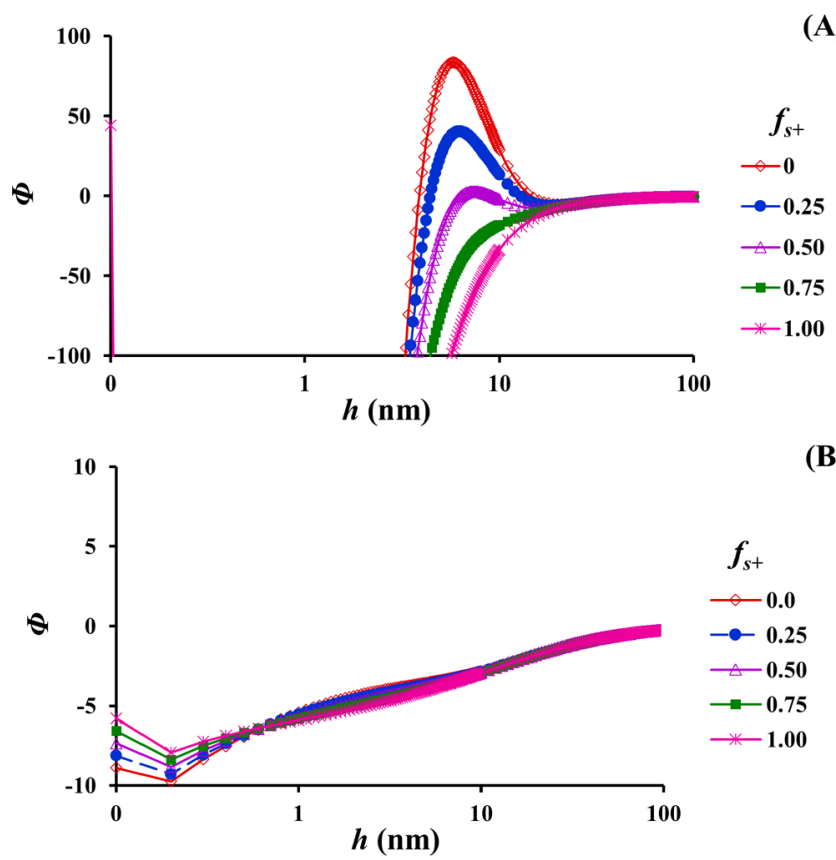

Figure 3. Dimensionless interaction energy profiles for the $\mathrm{CH}$-Both (A) and $\mathrm{CH}+\mathrm{NR}$-Both (B) conditions when $f_{\text {s+ }}$ was equal to $0.0,0.25$, $0.5,0.75$, and 1.0 and other $\mathrm{NR}$ and $\mathrm{CH}$ parameters were the same as in Figure 2 (Table 1).

profiles for the $\mathrm{CH}$-Both (Figure $3 \mathrm{~A}$ ) and $\mathrm{CH}+\mathrm{NR}-\mathrm{Both}$ (Figure $3 \mathrm{~B}$ ) conditions when $f_{s+}$ was equal to $0.0,0.25,0.5$, 0.75 , and 1.0 and other parameters were the same as in Figure 2 (Table 1). In the absence of NR (CH-Both), an increase in $f_{s+}$ from 0 to 0.25 decreased $\Phi_{\max }$ and $\Phi_{2 \min }$ and $\Phi_{\max }$ was eliminated when $f_{s+}=0.5,0.75$, and 1 . Furthermore, the depth of $\Phi_{1 \text { min }}$ was always very large $(<-4592.8)$. In contrast to $\mathrm{CH}$ Both (Figure $3 \mathrm{~A}$ ), the interaction energy profiles showed little sensitivity to changes in $f_{s+}$ from 0 to 1 when NR was included (Figure 3B). The value of $\Phi_{\max }$ was always eliminated, and $\Phi_{1 \text { min }}$ was shallow $(>-10)$. Although $\mathrm{CH}$ parameters played an important role in interaction energy profiles in the absence of NR (Figure 3A), Figure 3B clearly indicates that NR parameters controlled the interaction energy profiles in the $\mathrm{CH}+\mathrm{NR}-\mathrm{Both}$ calculations, even under electrostatically favorable conditions. These results are consistent with previous literature that has examined the influence of $\mathrm{CH}$ and $\mathrm{NR}$ on the $\mathrm{SWI}^{22,24}$ but now $\mathrm{CH}$ has an even smaller influence on interaction energy parameters and colloid retention when NR occurs on both the SWI and colloid.

In addition to roughness, the depth of $\Phi_{1 \text { min }}$ is also a function of the zeta potential and $\mathrm{CH}$ parameters. Figure $\mathrm{S} 2$ presents a plot of $\Phi_{1 \min }$ for an oocyst when the IS $=10 \mathrm{mM}$ and the zeta potential of the oocyst and the SWI were varied between -60 to $60 \mathrm{mV}$. Positive values of $\Phi_{1 \min }$ were obtained under highly repulsive electrostatic interactions (e.g., highly negative or positive values of both zeta potentials), whereas $\Phi_{1 \text { min }}$ decreased and became more negative as the electrostatic interaction became more attractive (e.g., the difference in the zeta potentials increased). The electrostatic interaction goes to zero as the zeta potentials of both the oocyst and SWI approach zero. An increase in $f_{s+}$ from 0 to 1 actually produced a decrease in magnitude of $\Phi_{1 \text { min }}$ in Figures $3 \mathrm{~A}$ and $3 \mathrm{~B}$ due to the near neutral value of $\zeta_{c-}(-6 \mathrm{mV})$ which produced a more attractive electrostatic interaction with $\zeta_{s_{-}}(-61.7 \mathrm{mV})$ than with $\zeta_{s_{+}}(10$ $\mathrm{mV})$. If $\zeta_{\mathrm{c}-}$ is more negatively charged or $\zeta_{s+}$ is more positively charged, then $\Phi_{1 \min }\left(\right.$ and $\left.\Phi_{\max }\right)$ will decrease with increasing $f_{\mathrm{s}+}$ as expected. ${ }^{53}$

Figure 4 shows contour plots of $\Phi_{1 \min }$ (Figure $\left.4 \mathrm{~A}\right), \Phi_{\max }$ (Figure $4 \mathrm{~B}$ ), and $\Phi_{2 \min }$ (Figure $4 \mathrm{C}$ ) for an oocyst and quartz sand for the $\mathrm{CH}+\mathrm{NR}-\mathrm{Both}$ condition when the $\mathrm{IS}=10 \mathrm{mM}$ $\mathrm{NaCl}$. Parameter values were the same as in Figure 2 (Table 1), with the exception that $f_{\text {sr }}=f_{\text {cr }}$ was now varied between 0.01 and 1 and $h_{\mathrm{sr}}=h_{\mathrm{cr}}$ ranged from 0 to $80 \mathrm{~nm}$. Note that interaction energy profile parameters were very sensitive to the roughness height and fraction. Primary minimum interactions were possible when $f_{\mathrm{sr}}=f_{\mathrm{cr}}$ was $\leq 0.25$ and $h_{\mathrm{sr}}=h_{\mathrm{cr}}$ was $\geq 10 \mathrm{~nm}$ because $\Phi_{\max }$ was less than 5 . In this case, the $f_{\text {sr }}=f_{\text {cr }}$ had a greater influence on the interaction energy parameters than $h_{\mathrm{sr}}=h_{\mathrm{cr}}$. For example, the value of $\Phi_{1 \min }$ became shallower with further decreases in $f_{\text {sr }}=f_{\text {cr. }}$. The value of $\Phi_{\max }$ significantly increased when $f_{\text {sr }}=f_{\text {cr }}$ was $>0.25$, such that the oocyst interaction was mainly limited to the secondary minimum, which became shallower for smaller $f_{\mathrm{sr}}=f_{\mathrm{cr}}$. The insensitivity of interaction energy parameters on $h_{\mathrm{sr}}=h_{\mathrm{cr}}$ at $\geq 10 \mathrm{~nm}$ is because the bulk colloid and collector surfaces receded very far, which had little influence on the total interaction energy. Similar to Figure 3B, variations in $\mathrm{CH}$ parameters were found to have a greater influence on interaction energy parameters when $f_{\mathrm{sr}}=f_{\mathrm{cr}}$ $>0.25$ (data not shown).

An alternative way of examining the roles of $\mathrm{NR}$ and $\mathrm{CH}$ on colloid immobilization is to present the energy balance results in terms of $\varepsilon_{1}, \varepsilon_{2}, \beta_{1}$, and $\beta_{2}$. For example, interaction energy parameters shown in Figure 4 were utilized in eqs 5 and 6 to determine $\varepsilon_{1}, \varepsilon_{2}$, and $\beta_{1}$ shown in Figure 5 as a function $f_{\mathrm{sr}}=f_{\mathrm{cr}}$ and of $h_{\mathrm{sr}}=h_{\mathrm{cr}}$. Consistent with Figure 4, $\varepsilon_{1}>0$ occurred when $f_{\mathrm{sr}}=f_{\mathrm{cr}}$ was $\leq 0.25$ and $h_{\mathrm{sr}}=h_{\mathrm{cr}}$ was $\geq 10 \mathrm{~nm}$, whereas $\varepsilon_{2}>0$ dominated oocyst immobilization for the opposite roughness conditions. Interestingly, values of $\beta_{2}$ were always zero and this indicates that oocyst interaction in the secondary minimum was always reversible. In contrast, some values of $\beta_{1}$ were 

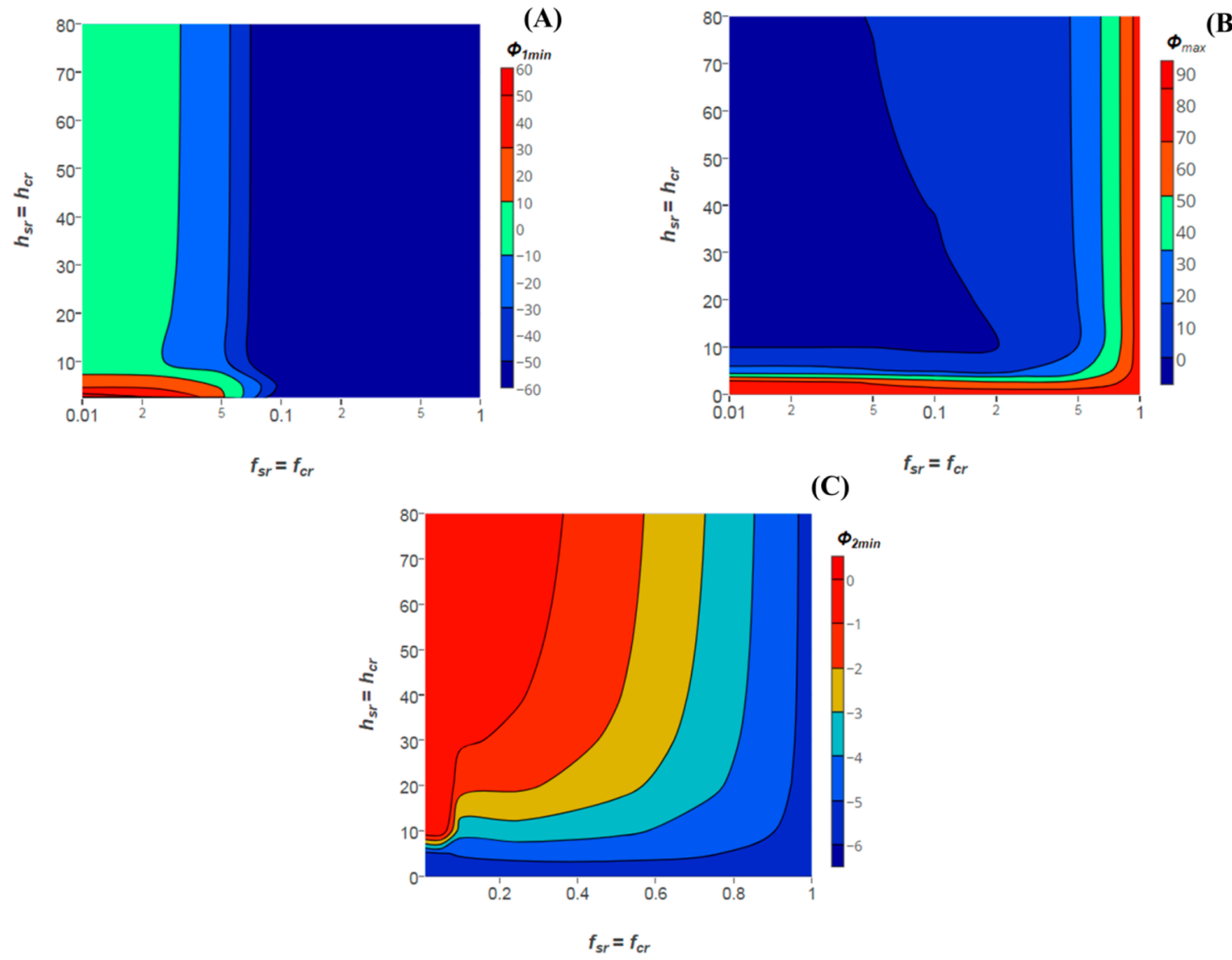

Figure 4. Contour plots of $\Phi_{1 \min }(\mathrm{A}), \Phi_{\max }(\mathrm{B})$, and $\Phi_{2 \min }(\mathrm{C})$ for an oocyst and quartz sand for the CH+NR-Both condition when the IS = $10 \mathrm{mM}$ $\mathrm{NaCl}$. Parameter values were the same as in Figure 2 (Table 1), with the exception that $f_{\mathrm{sr}}=f_{\mathrm{cr}}$ was now varied between 0.01 and 1 and $h_{\mathrm{sr}}=h_{\mathrm{cr}}$ ranged from 0 to $80 \mathrm{~nm}$. Values of $f_{\mathrm{sr}}=f_{\mathrm{cr}}$ are presented on a log scale in (A) and (B), whereas a linear scale is used in (C).

irreversible for the selected solution chemistry under certain roughness conditions. In particular, values of $\beta_{1}=1$ when 0.025 $\leq f_{\mathrm{sr}}=f_{\mathrm{cr}} \leq 0.25$ and $h_{\mathrm{sr}}=h_{\mathrm{cr}} \geq 10 \mathrm{~nm}$. It should be mentioned that eq 6 can be modified to incorporate the influence of flowing water on the torque balance and spatial variations in $\mathrm{NR}$ and $\mathrm{CH}$ heterogeneity parameters on the SWI. ${ }^{24}$ Consequently, this information can be used to design surfaces with specific roughness characteristics for reversible or irreversible colloids retention under selected physicochemical conditions, or to study colloid retention and release on natural heterogeneous surfaces.

The electrostatic double layer and van der Waals interactions are proportional to the colloid radius (eqs S2 and S3). Consequently, if other parameter values remain unchanged, then the magnitudes of $\Phi_{2 \min }, \Phi_{\max }$ and $\Phi_{1 \min }$ will decrease with decreasing colloid size. This information implies that the influence of $\mathrm{NR}$ and $\mathrm{CH}$ on interaction energy parameters is enhanced for small colloid sizes. To illustrate this point Figure 6 presents contour plots of $\varepsilon_{1}$ and $\beta_{1}$ for a $100 \mathrm{~nm}$ colloid as a function of $f_{\mathrm{sr}}=f_{\mathrm{cr}}$ and $h_{\mathrm{sr}}=h_{\mathrm{cr}}$ for the same conditions shown in Figure 5. In comparison to Figure 5, values of $\varepsilon_{1}>0$ and $\beta_{1}=$ 1 now occur over a wider range of roughness conditions. In particular, values of $\beta_{1}=1$ occurred when $f_{\mathrm{sr}}=f_{\mathrm{cr}} \geq 0.25$ and $h_{\mathrm{sr}}$ $=h_{\mathrm{cr}} \geq 2.5 \mathrm{~nm}$. Reversible primary and secondary minimum interactions were predicted when the IS $=10 \mathrm{mM}$ when $f_{\mathrm{sr}}=f_{\text {cr }}$ $<0.25$. Consequently, high mobility of nanoparticles is expected in systems with certain roughness conditions (low values of $f_{\text {sr }}$ and $f_{\text {cr }}$ ), but not for others. This finding is consistent with experimental observations for viruses. ${ }^{54}$

Input parameters for the electrostatic double layer interaction are strong functions of the solution chemistry. For example, changes in the solution IS are known to alter both the double layer thickness and the zeta potentials., ${ }^{9,12}$ Additional calculations were therefore performed to assess the influence of NR parameters on oocyst retention when the IS $=1,10$, and $100 \mathrm{mM}$. All secondary minimum interactions were reversible, whereas primary minimum interactions were reversible or irreversible depending on the influence that roughness parameters had on $\Phi_{\max }$ and $\Phi_{1 \text { min }}$. Figure 7 summarizes this information by presenting contour plots of $\beta_{1}$ for the oocysts as a function of $f_{\mathrm{sr}}=f_{\mathrm{cr}}$ (ranged from 0.01 to 1 ) and $h_{\mathrm{sr}}=h_{\mathrm{cr}}$ (ranged from 0 to $80 \mathrm{~nm}$ ) for the various IS conditions. A wider range in roughness parameters contributes to irreversible oocyst interaction $\left(\beta_{1}=1\right)$ as the IS increases due to compression of the double layer thickness and a reduction in $\Phi_{\max }$. This produces an increase in colloid retention with IS that has been experimentally observed. ${ }^{6,8,28}$ However, some roughness conditions still produced reversible interaction $\left(\beta_{1}=\right.$ $0)$ in the absence of $\Phi_{\max }$ when the IS $=100 \mathrm{mM}$ because of the presence of a shallow $\Phi_{1 \text { min }}$ that was susceptible to diffusive oocyst release. Consequently, only a fraction of the solid surface area may contribute to oocyst immobilization even in the absence of an energy barrier. This observation has been experimentally and theoretically confirmed previously. ${ }^{24,25,28,29}$ Interestingly, some roughness conditions (e.g., $0.025 \leq f_{\mathrm{sr}}=f_{\mathrm{cr}}$ 

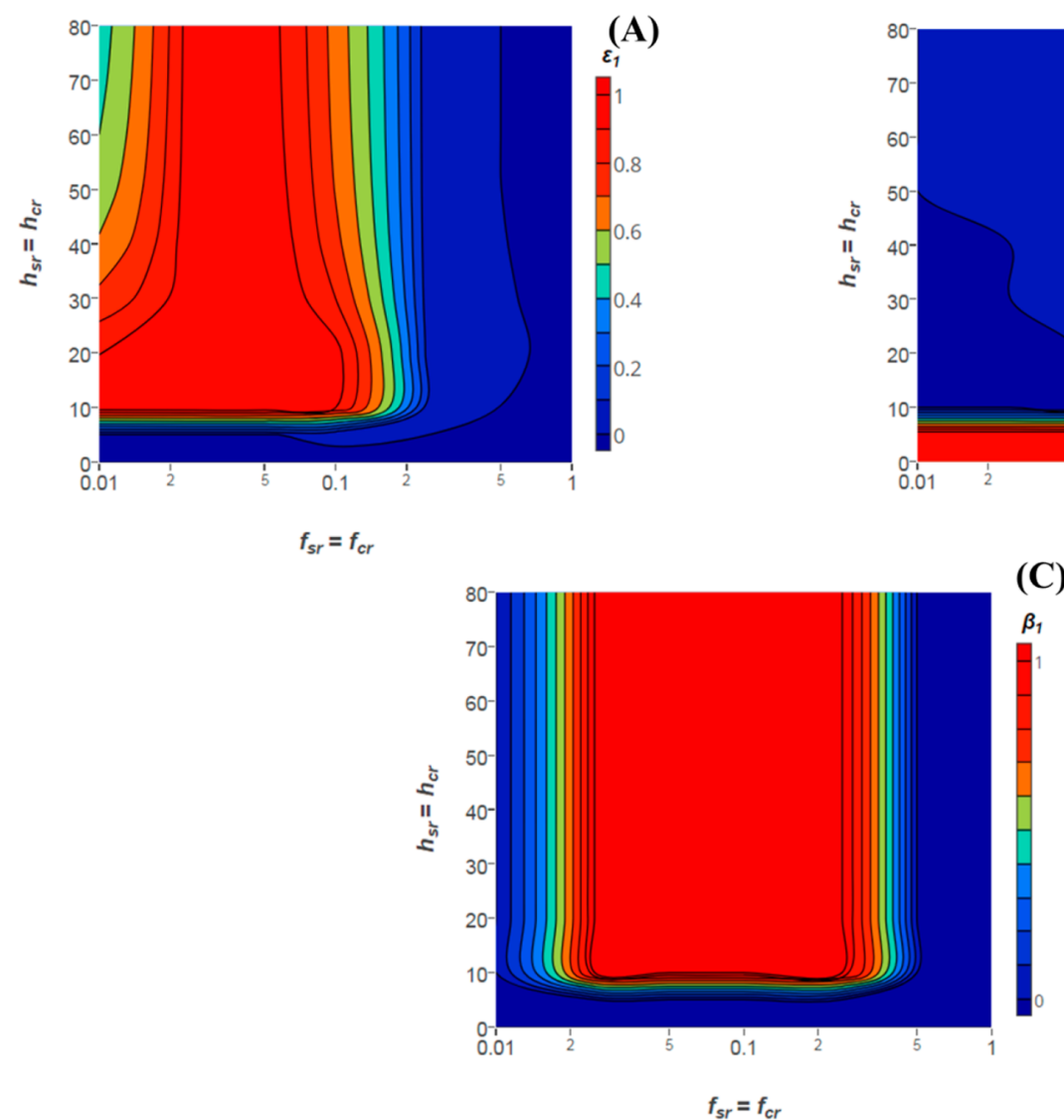

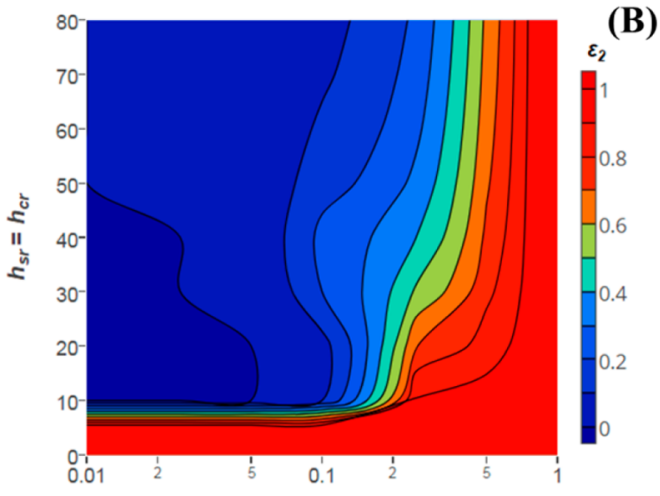

(C)

$f_{s r}=f_{c r}$

(B)

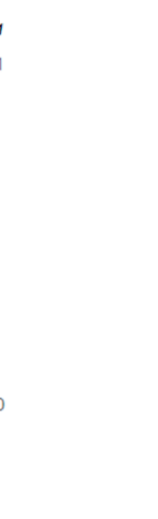

Figure 5. Contour plots of $\varepsilon_{1}(\mathrm{~A}), \varepsilon_{2}(\mathrm{~B})$, and $\beta_{1}(\mathrm{C})$ for an oocyst and quartz sand for the $\mathrm{CH}+\mathrm{NR}-\mathrm{Both}$ condition when the IS $=10 \mathrm{mM} \mathrm{NaCl}$. Parameter values were the same as in Figure 2 (Table 1), with the exception that $f_{\mathrm{sr}}=f_{\mathrm{cr}}$ was now varied between 0.01 and 1 (shown on a log scale) and $h_{\mathrm{sr}}=h_{\mathrm{cr}}$ ranged from 0 to $80 \mathrm{~nm}$. Values $0<\beta_{1}<1$ were interpolated by the graphing program.
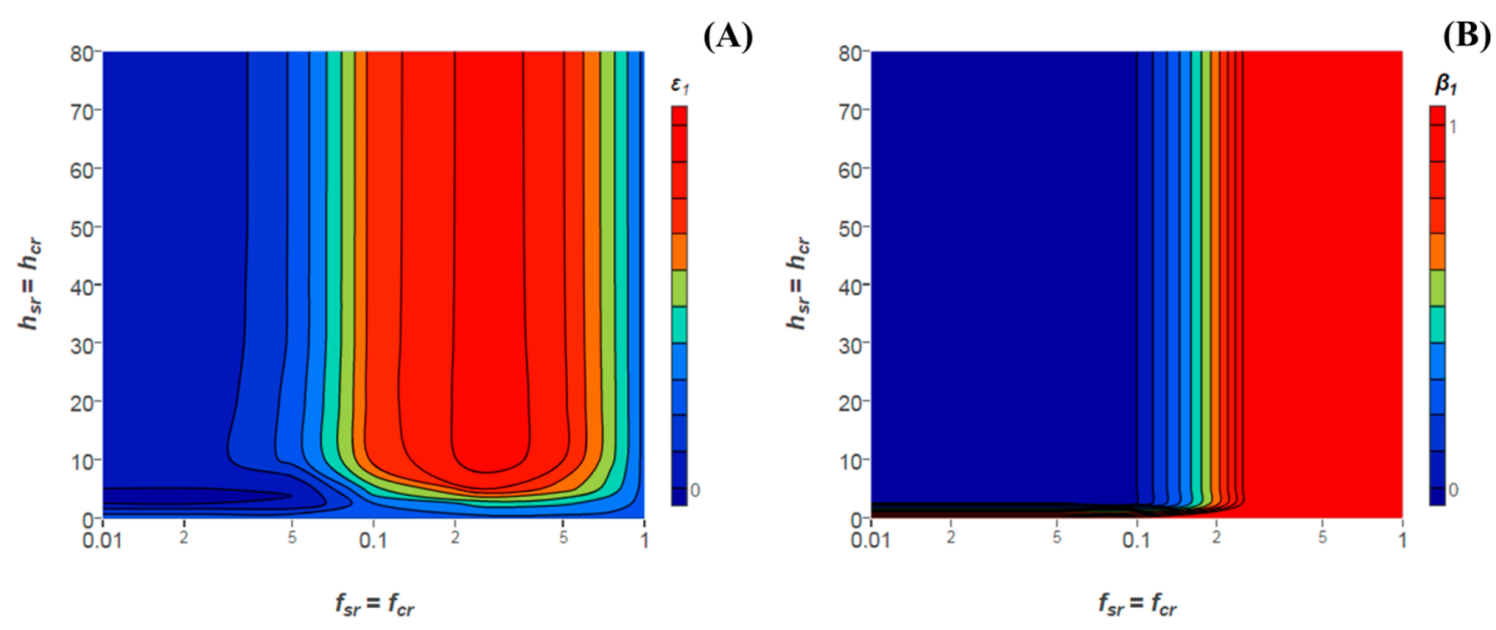

Figure 6. Contour plots of $\varepsilon_{1}(\mathrm{~A})$ and $\beta_{1}$ (B) for a $100 \mathrm{~nm}$ colloid and quartz sand for the $\mathrm{CH}+\mathrm{NR}-\mathrm{Both}$ condition when the $\mathrm{IS}=10 \mathrm{mM} \mathrm{NaCl}$. Other parameter values were the same as in Figure 2 (Table 1), with the exception that $f_{\mathrm{sr}}=f_{\mathrm{cr}}$ was now varied between 0.01 and 1 (shown on a log scale) and $h_{\mathrm{sr}}=h_{\mathrm{cr}}$ ranged from 0 to $80 \mathrm{~nm}$. Values $0<\beta_{1}<1$ were interpolated by the graphing program.

$\leq 0.05$ and $h_{\mathrm{sr}}=h_{\mathrm{cr}} \geq 10 \mathrm{~nm}$ ) transferred from irreversible to reversible interaction as the IS increased from 10 to $100 \mathrm{mM}$ because the magnitude of $\Phi_{1 \text { min }}$ decreased with compression of the double layer thickness. This issue will be further investigated subsequently.

Kim et al. ${ }^{26}$ observed a pronounced decrease in E. coli O157:H7 retention with an increase in solution IS. This trend is not consistent with interaction energy calculations for a homogeneous cell and SWI, and it has therefore been attributed to electrosteric repulsion. ${ }^{26}$ Interaction energy profiles between E. coli $\mathrm{O} 157: \mathrm{H} 7$ and quartz sand when the IS $=1,10$, and 100 $\mathrm{mM} \mathrm{NaCl}$ were determined over a range in $f_{\mathrm{sr}}=f_{\mathrm{cr}}(0.01-1)$ and $h_{\mathrm{sr}}=h_{\mathrm{cr}}(0-80)$ conditions to see if NR provides a viable alternative explanation. There was no energy barrier for cells to interact in a primary minimum for all roughness conditions because of the near neutral charge of the cell $\left(\zeta_{c-}\right.$ ranged from -2.1 to $-5.9 \mathrm{mV}$ as the IS increased from 1 to $100 \mathrm{mM}$ ) and negatively charged SWI $\left(\zeta_{s-}\right.$ ranging from -63.8 to $-29.8 \mathrm{mV}$ 

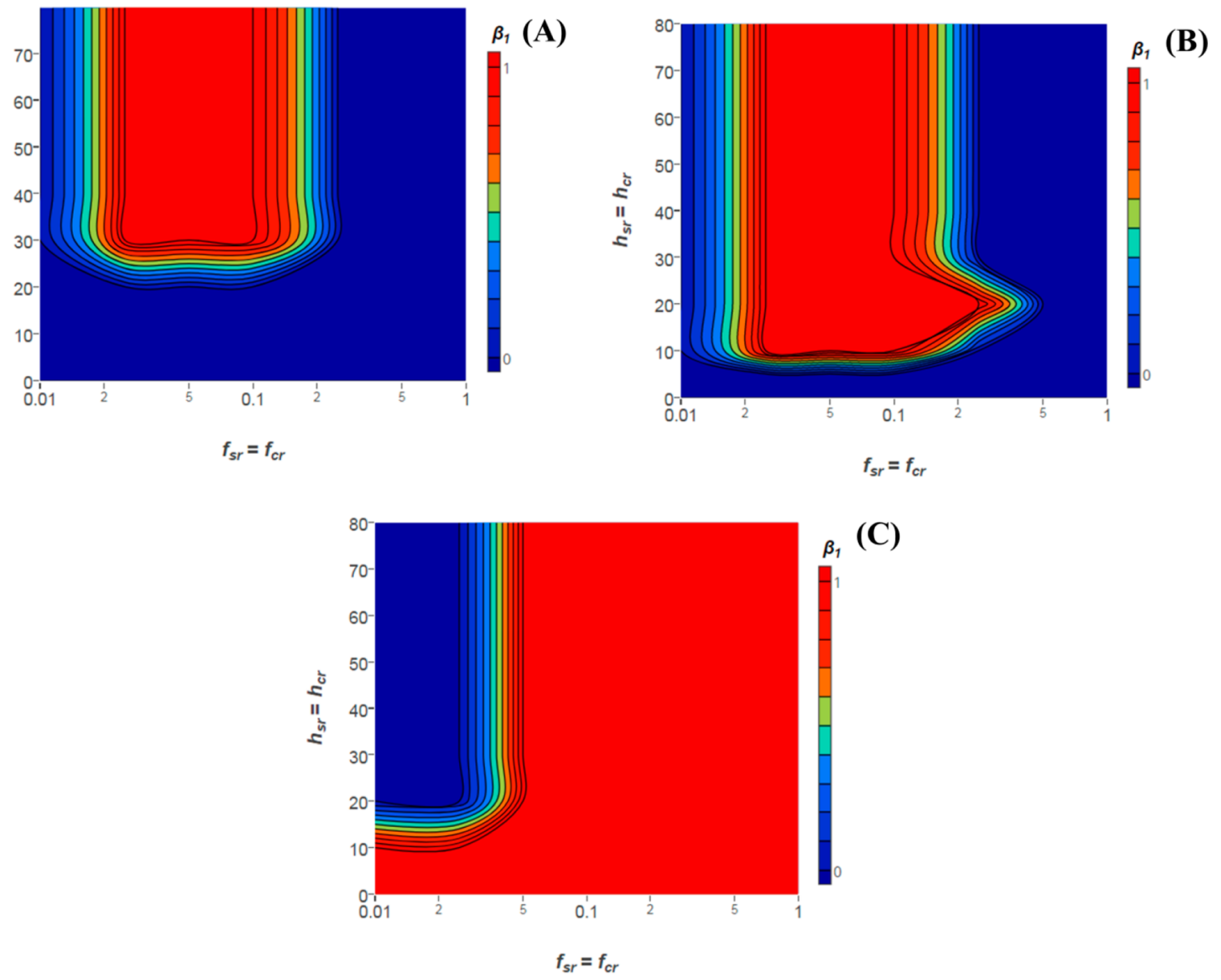

Figure 7. Contour plots of $\beta_{1}$ for an oocyst and quartz sand for the NR-Both condition when the IS = 1 (A), $10(\mathrm{~B})$, and $100(\mathrm{C}) \mathrm{mM} \mathrm{NaCl}$. Parameter values are given in Table 1 . Values $0<\beta_{1}<1$ were interpolated by the graphing program.

as the IS increased from 1 to $100 \mathrm{mM}$ ). Figure 8 presents a contour plot of $\beta_{1}$ as a function of $f_{\mathrm{sr}}=f_{\mathrm{cr}}$ and $h_{\mathrm{sr}}=h_{\mathrm{cr}}$ for the various IS conditions. Consistent with experimental observations of decreasing cell retention with increasing $\mathrm{IS}^{26}$ the number of roughness combinations that contributed to irreversible cell interaction $\left(\beta_{1}=1\right)$ decreased with an increase in IS. This occurred because an increase in IS produced a decrease in the magnitude of $\Phi_{1 \text { min }}$ that was shallow enough to allow an interacting cell to escape by diffusion on some rough surfaces. The decrease in magnitude of $\Phi_{1 \text { min }}$ with IS happened because of a decrease in the magnitude of the electrostatic interaction when the double layer thickness was compressed. Similarly, Elimelech ${ }^{55}$ demonstrated that the double layer attraction on a smooth, electrostatically favorable surface decreased with increasing IS due to screening effects.

The above results indicate the following conditions are needed to produce a decrease in colloid retention with increasing IS: (i) the absence of an energy barrier and (ii) shallow depths of the primary minimum. The absence of an energy barrier can be achieved under favorable electrostatic conditions or on unfavorable electrostatic surfaces with specific roughness fractions and heights to eliminate the energy barrier. Shallow depths of the primary minimum occur on surfaces with specific roughness, $\mathrm{CH}$, and zeta potential properties (as demonstrated in this paper), and are more common for smaller than larger colloids (comparison of Figures 5 and 6).

The stability of colloid suspensions has frequently been enhanced by adsorption of surfactants and polymers. ${ }^{32}$ The mechanism for this stability enhancement has commonly been attributed to electrosteric repulsion. ${ }^{32}$ The magnitudes of $\Phi_{2 \text { min }}$ $\Phi_{\max }$ and $\Phi_{1 \min }$ are smaller for a sphere-sphere than for a sphere-plate geometry when other conditions remain the same (eqs $\mathrm{S} 1-\mathrm{S} 5$ ). Consequently, $\mathrm{NR}$ and $\mathrm{CH}$ will have a greater impact for colloids interacting with another colloid than for the SWI. Figure 9 presents contour plots of $\beta_{1}$ for a 100, 1000, and $5000 \mathrm{~nm}$ colloid suspension as a function of $f_{\text {cr }}(0.01$ to 1$)$ and $h_{\mathrm{cr}}(0$ to $80 \mathrm{~nm})$ when the solution IS $=100 \mathrm{mM}$ and $\zeta_{\mathrm{c}-}=$ $-10 \mathrm{mV}$. There was no energy barrier between colloid-colloid interactions in the absence of surface roughness, and $\Phi_{1 \text { min }}$ was sufficiently deep to produce irreversible aggregation $\left(\beta_{1}=1\right)$. In this case, the colloid suspension is unstable. Conversely, NR can produce a shallow $\Phi_{1 \text { min }}$ that leads to reversible colloidcolloid interactions and a stable colloid suspension in some cases $\left(\beta_{1}=0\right)$. However, the roughness parameters that produced a stable colloid suspension changed with the colloid size. In particular, smaller colloids were stabilized over a wider range of roughness parameters than larger colloids; e.g., 100, 1000 , and $5000 \mathrm{~nm}$ colloids were stabilized when $f_{\mathrm{cr}} \leq 0.25$ and $h_{\mathrm{cr}} \geq 2.5 \mathrm{~nm}, f_{\mathrm{cr}} \leq 0.1$ and $h_{\mathrm{cr}} \geq 10 \mathrm{~nm}$, and $f_{\mathrm{cr}} \leq 0.05$ and $h_{\mathrm{cr}} \geq$ $20 \mathrm{~nm}$, respectively. Consequently, NR on colloids provides a viable alternative explanation for stabilized colloid suspensions and disaggregation of colloid suspensions under favorable electrostatic conditions. It should be mentioned that differences in the colloid zeta potential and solution chemistry will also influence the roughness parameters that are needed to produce a stable colloid suspension. This same approach can be used to 

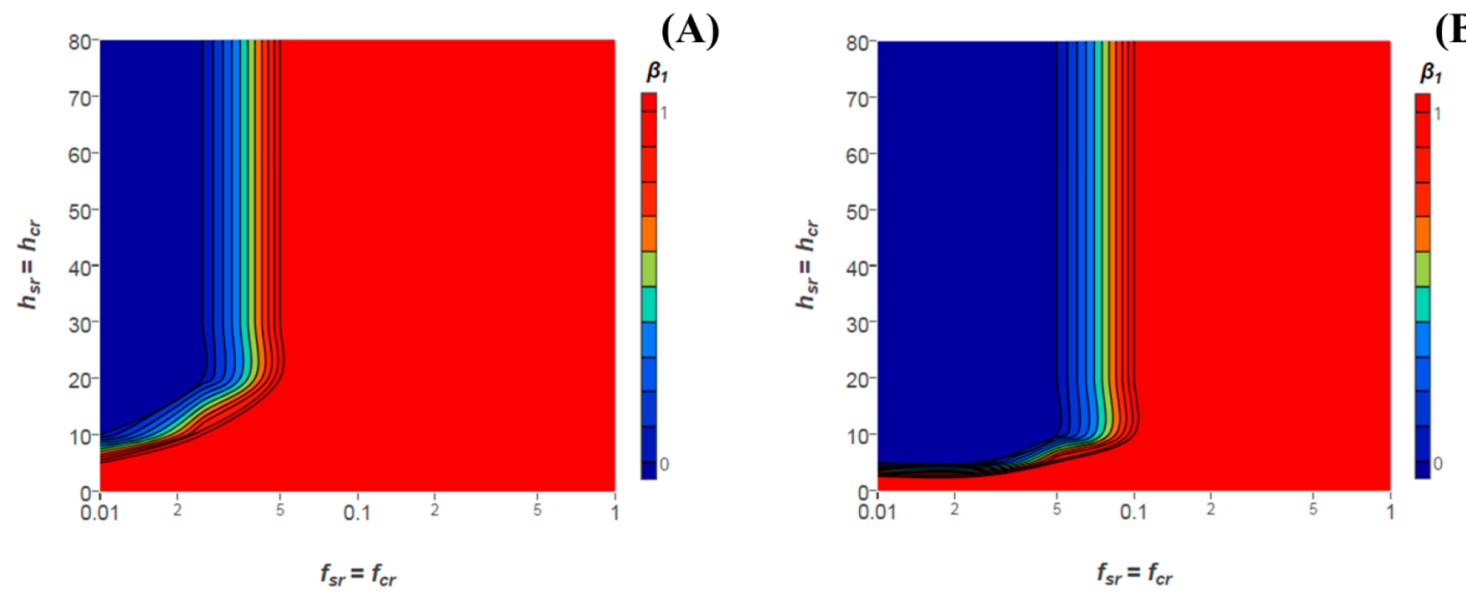

(B)

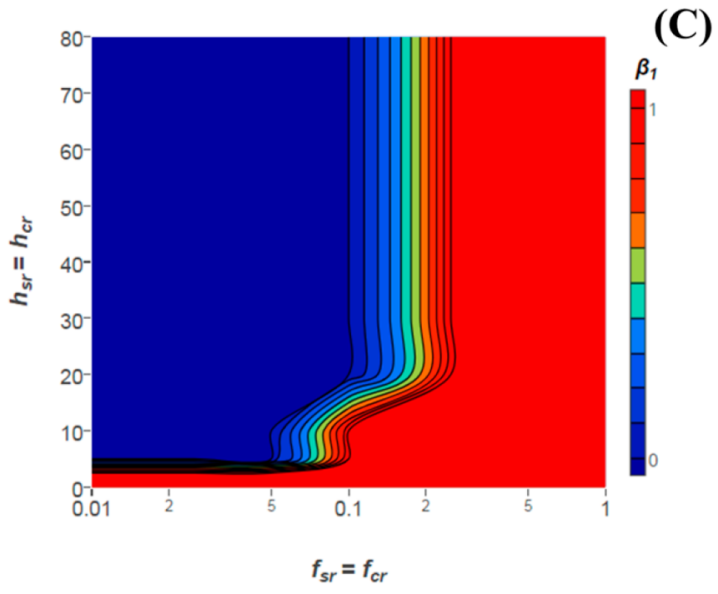

(C)

Figure 8. Contour plots of $\beta_{1}$ for an E. coli O157:H7 and quartz sand for the NR-Both condition when the IS = 1 (A), 10 (B), and 100 (C) mM $\mathrm{NaCl}$. Parameter values are given in Table 1 . Values $0<\beta_{1}<1$ were interpolated by the graphing program.

systematically study these fundamental issues for many commercial and industrial applications.

\section{CONCLUSIONS}

An approach was developed to determine the interaction energy between a colloid and the SWI or another colloid that accounts for binary $\mathrm{NR}$ and $\mathrm{CH}$ on both surfaces. In particular, the mean interaction energy was determined as a linear combination of interaction energies associated with the NR and $\mathrm{CH}$ fractions on both surfaces within the zone of electrostatic influence. Numerical experiments were subsequently conducted to investigate the roles of $\mathrm{NR}$ and $\mathrm{CH}$ parameters, colloid size, and solution IS on interaction energy parameters, the probability for colloid immobilization and release, and reversible and irreversible retention or aggregation. $\mathrm{CH}$ primarily influenced the interaction energy by reducing the energy barrier and increasing the depths of the primary and secondary minima when the SWI was smooth, especially for higher $\mathrm{CH}$ fractions, for smaller colloid sizes, and higher IS. In contrast, NR controlled adhesive interactions for a wide range of $\mathrm{CH}$ and IS conditions by reducing the energy barrier height and magnitudes of the primary and secondary minima. These effects of NR were magnified when roughness occurred on both interacting surfaces, for lower values of roughness fractions, for smaller colloid sizes, and for colloid-colloid than colloid-SWI interactions. Roughness mainly produced primary minimum interactions, even under electrostatically unfavorable conditions, that were reversible or irreversible depending on the roughness fraction and height. The influence of NR was also coupled with the solution IS due to its influence on the zeta potentials and the double layer thickness. An increase in solution IS tended to produce an even shallower primary minimum. Consequently, changes in solution IS influenced the NR combinations that contributed to reversible and irreversible colloid retention and suspension stability. Only a fraction of the roughness combinations produced irreversible colloid retention in the absence of an energy barrier. Not all the surface area is therefore expected to contribute to colloid retention under electrostatically favorable conditions. In the presence of an energy barrier, an increase in IS produced more NR combinations for irreversible retention, and colloid retention was therefore expected to increase with IS. Conversely, in the absence of an energy barrier, an increase in IS produced a decrease in irreversible colloid retention when the primary minimum was shallow. These observations indicate that NR can provide a viable alternative explanation for anomalous colloid retention and stability behavior that has previously been attributed to electrosteric repulsion (e.g., a decrease in colloid retention with an increase in solution IS; reversible colloid retention under favorable conditions; and diminished colloid retention and enhanced colloid stability due to adsorbed surfactants, polymers, and/or humic materials that alter roughness properties). The developed approach can be used 

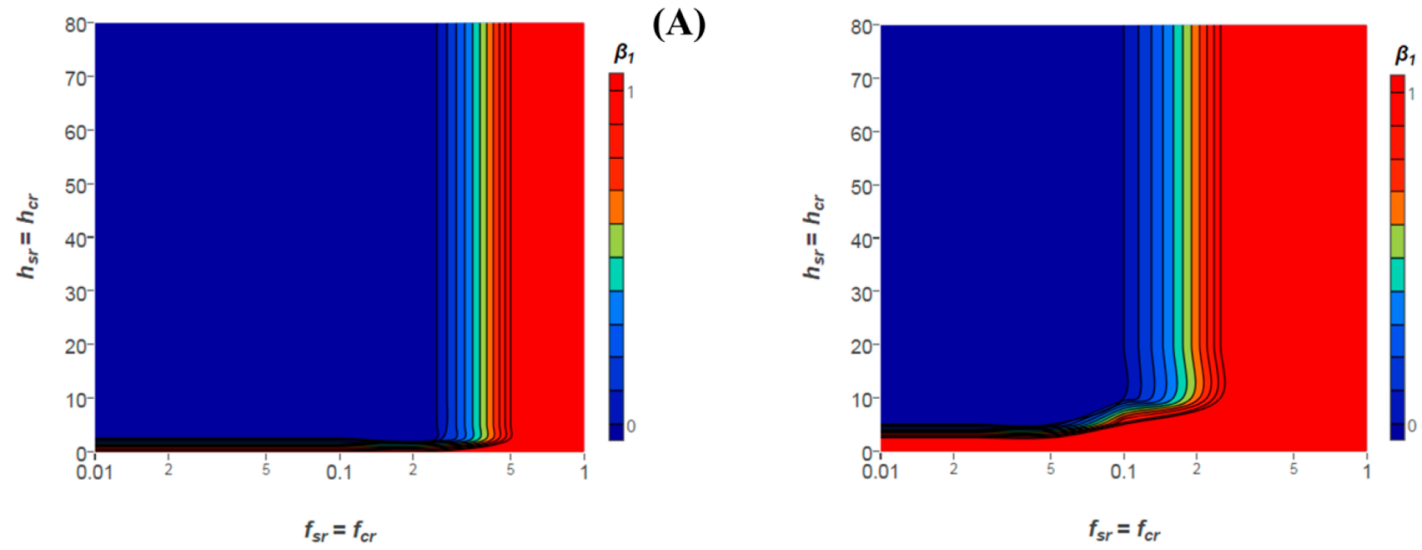

(B)

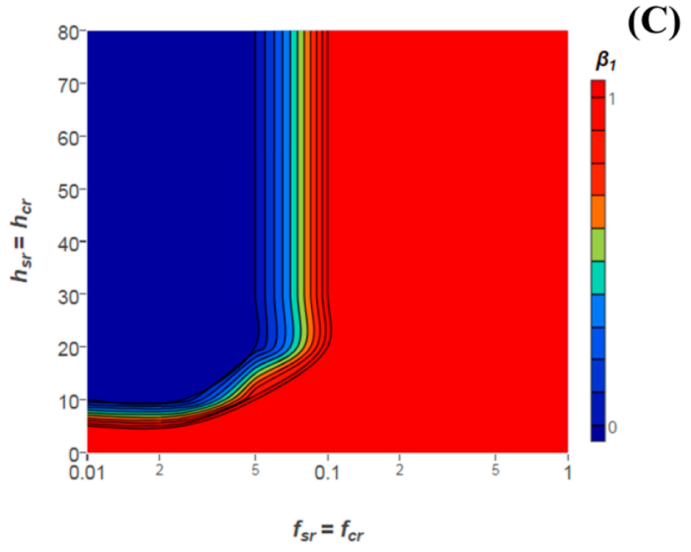

Figure 9. Contour plots of $\beta_{1}$ for 100 (A), 1000 (B), and 5000 (C) nm sized colloids for the NR-Both condition when the IS = $100 \mathrm{mM} \mathrm{NaCl}$. Colloid-colloid interactions are considered and parameter values are given in Table 1 . In this case, $h_{s r}=h_{c r}$ and $f_{s r}=f_{c r}$ denotes that the roughness height and fraction, respectively, were the same on both colloids. Values $0<\beta_{1}<1$ were interpolated by the graphing program.

to design surfaces with specific $\mathrm{NR}$ and $\mathrm{CH}$ features to enhance or diminish colloid retention and/or stability. It can also be employed to investigate colloid retention and stability on natural surfaces that exhibit distributions of roughness parameters.

\section{ASSOCIATED CONTENT}

\section{S Supporting Information}

The Supporting Information is available free of charge on the ACS Publications website at DOI: 10.1021/acs.langmuir.7b02445.

Interaction energy calculations (S1); plot of $\varepsilon_{1}$ as a function of $\Phi_{\max }$ when $\Phi_{2 \min }=0$ and $\Phi_{1 \min }=-\infty$ (unfavorable electrostatic conditions), and $\varepsilon_{\mathrm{r} 1}$ as a function of $\Phi_{1 \min }$ when $\Phi_{2 \min }=0$ and $\Phi_{\max }=0$ (favorable electrostatic conditions); plots of $\Phi_{1 \min }$ for a physically and chemically homogeneous oocyst and SWI when the IS $=10 \mathrm{mM}$ and the zeta potential of the oocyst and the SWI was varied between -60 and $60 \mathrm{mV}$ (PDF)

\section{AUTHOR INFORMATION}

\section{Corresponding Author}

*Phone: 951-369-4857. E-mail: Scott.Bradford@ars.usda.gov.

\section{ORCID}

Scott A. Bradford: 0000-0002-3260-2968

\section{Notes}

The authors declare no competing financial interest.

\section{ACKNOWLEDGMENTS}

This research was supported by the USDA, ARS, National Program 212.

\section{REFERENCES}

(1) Santore, M. M.; Kalasin, S. University Of Massachusetts. Nanopatterned surfaces and related methods for selective adhesion, sensing and separation. U.S. Patent 2012, 8,117,902.

(2) Henze, M.; van Loosdrecht, M. C.; Ekama, G. A.; Brdjanovic, D., Eds. Biological wastewater treatment; IWA publishing, 2008.

(3) Vidali, M. Bioremediation. an overview. Pure Appl. Chem. 2001, 73 (7), 1163-1172.

(4) Ashbolt, N. J. Microbial contamination of drinking water and human health from community water systems. Curr. Environ. Health Rep. 2015, 2 (1), 95-106.

(5) Šimůnek, J.; He, C.; Pang, L.; Bradford, S.A. Colloid-facilitated solute transport in variably saturated porous media. Vadose Zone J. 2006, 5 (3), 1035-1047.

(6) Khilar, K. C.; Fogler, H. S. Migrations of fines in porous media; Springer Science \& Business Media, 1998; Vol. 12.

(7) Levantesi, C.; La Mantia, R.; Masciopinto, C.; Böckelmann, U.; Ayuso-Gabella, M. N.; Salgot, M.; Tandoi, V.; Van Houtte, E.; Wintgens, T.; Grohmann, E. Quantification of pathogenic microorganisms and microbial indicators in three wastewater reclamation and managed aquifer recharge facilities in Europe. Sci. Total Environ. 2010, 408 (21), 4923-4930. 
(8) Ryan, J. N.; Elimelech, M. Colloid mobilization and transport in groundwater. Colloids Surf., A 1996, 107, 1-56.

(9) Elimelech, M.; Gregory, J.; Jia, X. Particle deposition and aggregation: measurement, modelling and simulation; ButterworthHeinemann, 2013.

(10) Derjaguin, B. V.; Landau, L. D. Theory of the stability of strongly charged lyophobic sols and of the adhesion of strongly charged particles in solutions of electrolytes. Acta Physicochim. U.S.S.R 1941, 14, 733-762.

(11) Verwey, E. J. W.; Overbeek, J.; Th, G. Theory of the stability of lyophobic colloids; Elsevier: Amsterdam, 1948.

(12) Israelachvili, J. N. Intermolecular and surface forces; Academic Press, San Diego, CA, 1992.

(13) Vaidyanathan, R.; Tien, C. Hydrosol deposition in granular media under unfavorable surface conditions. Chem. Eng. Sci. 1991, 46, 967-983.

(14) Suresh, L.; Walz, J. Y. Effect of surface roughness on the interaction energy between a colloidal sphere and a flat plate. J. Colloid Interface Sci. 1996, 183, 199-213.

(15) Huang, X.; Bhattacharjee, S.; Hoek, E. M. V. Is surface roughness a "scapegoat" or a primary factor when defining particlesubstrate interactions? Langmuir 2010, 26, 2528-2537.

(16) Bendersky, M.; Davis, J. M. DLVO interaction of colloidal particles with topographically and chemically heterogeneous surfaces. J. Colloid Interface Sci. 2011, 353, 87-97.

(17) Bhattacharjee, S.; Ko, C.-H.; Elimelech, M. DLVO interaction between rough surfaces. Langmuir 1998, 14, 3365-3375.

(18) Hoek, E. M. V; Bhattacharjee, S.; Elimelech, M. Effect of membrane surface roughness on colloid-membrane DLVO interactions. Langmuir 2003, 19, 4836-4847.

(19) Hoek, E. M. V.; Agarwal, G. K. Extended DLVO interactions between spherical particles and rough surfaces. J. Colloid Interface Sci. 2006, 298, 50-58.

(20) Henry, C.; Minier, J.-P.; Lefevre, G.; Hurisse, O. Numerical study on the deposition rate of hematite particle on polypropylene walls: Role of surface roughness. Langmuir 2011, 27, 4603-4612.

(21) Shen, C.; Li, B.; Wang, C.; Huang, Y.; Jin, Y. Surface roughness effect on deposition of nano- and micro-sized colloids in saturated columns at different solution ionic strengths. Vadose Zone J. 2011, 10, $1071-1081$.

(22) Bradford, S. A.; Torkzaban, S. Colloid interaction energies for physically and chemically heterogeneous porous media. Langmuir 2013, 29, 3668-3676.

(23) Bradford, S. A.; Torkzaban, S. Colloid adhesive parameters for chemically heterogeneous porous media. Langmuir 2012, 28, 1364313651.

(24) Bradford, S. A.; Torkzaban, S. Determining parameters and mechanisms of colloid retention and release in porous media. Langmuir 2015, 31 (44), 12096-12105.

(25) Zhang, M.; Bradford, S. A.; Šimůnek, J.; Vereecken, H.; Klumpp, E. Do goethite surfaces really control the transport and retention of multi-walled carbon nanotubes in chemically heterogeneous porous media? Environ. Sci. Technol. 2016, 50 (23), 12713-12721.

(26) Kim, H. N.; Bradford, S. A.; Walker, S. L. Escherichia coli O157: $\mathrm{H} 7$ transport in saturated porous media: Role of solution chemistry and surface macromolecules. Environ. Sci. Technol. 2009, 43 (12), 4340-4347.

(27) Rijnaarts, H. H. M.; Norde, W.; Lyklema, J.; Zehnder, A. J. B. DLVO and steric contributions to bacterial deposition in media of different ionic strengths. Colloids Surf., B 1999, 14, 179-195.

(28) Kim, H. N.; Walker, S. L.; Bradford, S. A. Coupled factors influencing the transport and retention of Cryptosporidium parvum oocysts in saturated porous media. Water Res. 2010, 44 (4), 12131223.

(29) Kuznar, Z. A.; Elimelech, M. Role of surface proteins in the deposition kinetics of Cryptosporidium oocysts. Langmuir 2005, 21, $710-716$.
(30) Kretzschmar, R.; Sticher, H. Transport of humic-coated iron oxide colloids in a sandy soil: Influence of $\mathrm{Ca} 2+$ and trace metals. Environ. Sci. Technol. 1997, 31 (12), 3497-3504.

(31) Keller, A. A.; Wang, H.; Zhou, D.; Lenihan, H. S.; Cherr, G.; Cardinale, B. J.; Miller, R.; Ji, Z. Stability and aggregation of metal oxide nanoparticles in natural aqueous matrices. Environ. Sci. Technol. 2010, 44 (6), 1962-1967.

(32) Schramm, L. L. Suspensions: basic principles. In Suspensions: Fundamentals and Applications in the Petroleum Industry, Advances in Chemistry Series, 251; Schramm, L. L., Eds.; American Chemical Society: Washington, DC, 1996; pp 463.

(33) Duffadar, R. D.; Davis, J. M. Dynamic adhesion behavior of micrometer-scale particles flowing over patchy surfaces with nanoscale electrostatic heterogeneity. J. Colloid Interface Sci. 2008, 326, 18-27.

(34) Shen, C.; Wang, F.; Li, B.; Jin, Y.; Wang, L.-P.; Huang, Y. Langmuir 2012, 28, 14681-14692.

(35) Bhattacharjee, S.; Elimelech, M. Surface element integration: A novel technique for evaluation of DLVO interaction between a particle and a flat plate. J. Colloid Interface Sci. 1997, 193, 273-285.

(36) Hogg, R.; Healy, T. W.; Fuerstenau, D. W. Mutual coagulation of colloidal dispersions. Trans. Faraday Soc. 1966, 62, 1638-1651.

(37) Gregory, J. Approximate expression for retarded van der Waals interaction. J. Colloid Interface Sci. 1981, 83, 138-145.

(38) Ruckenstein, E.; Prieve, D. C. Adsorption and desorption of particles and their chromatographic separation. AIChE J. 1976, 22, 276-285.

(39) Oliveira, R. Understanding adhesion: a means for preventing fouling. Exp. Therm. Fluid Sci. 1997, 14, 316-322.

(40) Simoni, S. F.; Harms, H.; Bosma, T. N. P.; Zehnder, A. J. B. Population heterogeneity affects transport of bacteria through sand columns at low flow rates. Environ. Sci. Technol. 1998, 32, 2100-2105.

(41) Shen, C.; Li, B.; Huang, Y.; Jin, Y. Kinetics of coupled primaryand secondary-minimum deposition of colloids under unfavorable chemical conditions. Environ. Sci. Technol. 2007, 41, 6976-6982.

(42) Bhattacharjee, S.; Chen, J. Y.; Elimelech, M. DLVO interaction energy between spheroidal particles and a flat surface. Colloids Surf., $A$ 2000, 165 (1-3), 143-156.

(43) Wu, L.; Gao, B.; Tian, Y.; Munoz-Carpena, R.; Zigler, K. J. DLVO interactions of carbon nanotubes with isotropic planar surfaces. Langmuir 2013, 29 (12), 3976-3988.

(44) Liu, Q.; Lazouskaya, V.; He, Q.; Jin, Y. Effect of particle shape on colloid retention and release in saturated porous media. J. Environ. Qual. 2010, 39 (2), 500-508.

(45) van Oss, C. J. Interfacial Forces in Aqueous Media; Marcel Dekker: New York, 1994.

(46) Han, Y.; Hwang, G.; Kim, D.; Bradford, S. A.; Lee, B.; Eom, I.; Kim, P. J.; Choi, S. Q.; Kim, H. Transport, retention, and long-term release behavior of $\mathrm{ZnO}$ nanoparticle aggregates in saturated quartz sand: Role of solution $\mathrm{pH}$ and biofilm coating. Water Res. 2016, 90, 247-257.

(47) Rasmuson, A.; Pazmino, E.; Assemi, S.; Johnson, W. P. Contribution of nano-to microscale roughness to heterogeneity: Closing the gap between unfavorable and favorable colloid attachment conditions. Environ. Sci. Technol. 2017, 51 (4), 2151-2160.

(48) Considine, R. F.; Dixon, D. R.; Drummond, C. J. Laterallyresolved force microscopy of biological microspheres-Oocysts of Cryptosporidium parvum. Langmuir 2000, 16, 1323-1330.

(49) Considine, R. F.; Drummond, C. J.; Dixon, D. R. Force of interaction between a biocolloid and an inorganic oxide: complexity of surface deformation, roughness, and brushlike behavior. Langmuir 2001, 17 (20), 6325-6335.

(50) Considine, R. F.; Dixon, D. R.; Drummond, C. J. Oocysts of Cryptosporidium parvum and model sand surfaces in aqueous solutions: an atomic force microscope (AFM) study. Water Res. 2002, 36, 34213428.

(51) Song, L. F.; Johnson, P. R; Elimelech, M. Kinetics of colloid deposition onto heterogeneously charged surfaces in porous media. Environ. Sci. Technol. 1994, 28, 1164-1171. 
(52) Tufenkji, N.; Elimelech, M. Breakdown of colloid filtration theory: Role of the secondary energy minimum and surface charge heterogeneities. Langmuir 2005, 21 (3), 841-852.

(53) Shen, C.; Lazouskaya, V.; Zhang, H.; Li, B.; Jin, Y.; Huang, Y. Influence of surface chemical heterogeneity on attachment and detachment of microparticles. Colloids Surf., A 2013, 433, 14-29.

(54) Sadeghi, G.; Schijven, J. F.; Behrends, T.; Hassanizadeh, S. M.; Gerritse, J.; Kleingeld, P. J. Systematic study of effects of $\mathrm{pH}$ and ionic strength on attachment of phage PRD1. Groundwater 2011, 49 (1), $12-19$.

(55) Elimelech, M. Kinetics of capture of colloidal particles in packed beds under attractive double layer interactions. J. Colloid Interface Sci. 1991, 146 (2), 337-352. 


\section{Contributions of Nanoscale Roughness to} Anomalous Colloid Retention and Stability Behavior

5

6 Scott A. Bradford ${ }^{1}$, Hyunjung $\mathrm{Kim}^{2}$, Chongyang Shen ${ }^{3}$, Salini Sasidharan ${ }^{4}$, and Jianying Shang ${ }^{3}$ 7

${ }^{1}$ US Salinity Laboratory, USDA, ARS, Riverside, CA

${ }^{2}$ Department of Mineral Resources and Energy Engineering, Chonbuk National University, 66414 Duckjin, Jeonju, Jeonbuk 561-756, Republic of Korea

${ }^{3}$ Department of Soil and Water Sciences, China Agricultural University, Beijing, China 100193

2

${ }^{4}$ Department of Environmental Sciences, University of California, Riverside, 92521

13

14

Revised

16

\section{Langmuir}

17

August 23, 2017

18

19 Pages: 5

20 Figures: 2

21

22

23 


\section{Supporting Information}

The supporting information contains details pertaining to interactions energy calculations

26 (S1). Figure S1 presents a plot of $\varepsilon_{1}$ as a function of $\Phi_{\max }$ when $\Phi_{2 \min }=0$ and $\Phi_{1 \min }=-\infty$

27 (unfavorable electrostatic conditions), and $\varepsilon_{r 1}$ as a function of $\Phi_{1 \min }$ when $\Phi_{2 \min }=0$ and $\Phi_{\max }=0$

28 (favorable electrostatic conditions). Figure S2 presents plots of $\Phi_{1 \min }$ for a physically and

29 chemically homogeneous oocyst and SWI when the IS=10 $\mathrm{mM}$ and the zeta potential of the

30 oocyst and the SWI were varied between -60 to $60 \mathrm{mV}$. This information is available free of

31 charge via the Internet at http://pubs.acs.org

\section{S1 - Interaction Energy Calculations}

The value of $\Phi_{s}$ between a colloid and the SWI, or another colloid, was considered to be

34 the sum of electrostatic, van der Waals, and Born repulsion interaction energies:

$35 \quad \Phi_{S}(h)=\Phi_{s}^{e l}(h)+\Phi_{s}^{v d W}(h)+\Phi_{s}^{B o r n}(h)$

36 where $\Phi_{s}^{e l}\left[\mathrm{ML}^{2} \mathrm{~T}^{-2}\right], \Phi_{s}^{v d W}\left[\mathrm{ML}^{2} \mathrm{~T}^{-2}\right]$, and $\Phi_{s}^{\text {Born }}\left[\mathrm{ML}^{2} \mathrm{~T}^{-2}\right]$ are the electrostatic, van der Waals,

37 and Born interaction energies on the smooth surface, respectively. The value of $\Phi_{s}^{e l}$ was

38 determined using the constant surface potential interaction expression of Hogg et al. ${ }^{1}$ for a

39 sphere-plate interaction as:

40

$\Phi_{s}^{e l}(h)=\pi \varepsilon \varepsilon_{0} r_{c}\left\{2 \zeta_{1} \zeta_{2} \ln \left[\frac{1+\exp (-\kappa h)}{1-\exp (-\kappa h)}\right]+\left(\zeta_{1}^{2}+\zeta_{2}^{2}\right) \ln [1-\exp (-2 \kappa h)]\right\}$

41 where $\varepsilon$ (dimensionless) is the dielectric constant of the medium, $\varepsilon_{0}\left[\mathrm{M}^{-1} \mathrm{~L}^{-3} \mathrm{~T}^{4} \mathrm{~A}^{-2}\right.$, where $\mathrm{A}$

42 denotes ampere] is the permittivity in a vacuum, $r_{c}[\mathrm{~L}]$ is the colloid radius, $\zeta_{1}$ is the zeta

43 potential of the colloid, $\zeta_{2}$ is the zeta potential of the collector, and $\kappa\left[\mathrm{L}^{-1}\right]$ is the Debye-Huckel 
44 parameter. The value of $\Phi_{s}^{v d W}$ for a sphere-plate interaction was determined using the expression 45 by Gregory ${ }^{2}$ as:

$46 \quad \Phi_{S}^{v d W}(h)=-\frac{A_{123} r_{c}}{6 h}\left[1+\frac{14 h}{\lambda}\right]^{-1}$

47 where $A_{123}\left[\mathrm{ML}^{2} \mathrm{~T}^{-2}\right.$ is the Hamaker constant, and $\lambda$ is a characteristic wavelength that was taken

48 as $100 \mathrm{~nm}^{2}$ The value of $\Phi_{s}^{\text {Born }}$ was calculated from Ruckenstein and Prieve $\mathrm{e}^{3}$ for a sphere-plate

49 interactions as:

$50 \quad \Phi_{S}^{B o r n}(h)=\frac{A_{123} \sigma_{c}^{6}}{7560}\left[\frac{8 r_{c}+h}{\left(2 r_{c}+7\right)^{7}}+\frac{6 r_{c}-h}{h^{7}}\right]$

51 The collision diameter, $\sigma_{c}$, was taken as $0.26 \mathrm{~nm}$ in order to achieve a primary minimum depth at

$520.157 \mathrm{~nm}$, a commonly accepted distance of closest approach. ${ }^{4}$

53 Slightly modified versions of Eqs. [S2] and [S3] were employed for colloid-colloid

54 interactions. In particular, the value of $r_{c}$ was replaced by $r_{c 1} r_{c 2} /\left(r_{c 1}+r_{c 2}\right)$ for sphere-sphere

55 interactions; where $r_{c 1}$ [L] and $r_{c 2}$ [L] are the radii of two colloids denoted with subscripts 1 and

562 , respectively. Unfortunately, Eq. [S4] cannot be simply modified in a similar manner to

57 determine the Born repulsion for sphere-sphere geometry. In this case, the expression of

58 Oliveira $^{5}$ was employed to determine Born repulsion as:

$59 \quad \Phi_{S}^{B o r n}(h)=\frac{A_{123} H_{\min }^{6}}{168 h^{7}}\left[\frac{r_{c 1} r_{c 2}}{r_{c 1}+r_{c 2}}\right]$

60 where $H_{\min }[\mathrm{L}]$ is the value of closest approach equal to $0.157 \mathrm{~nm}$.

61 All interaction energies were made dimensionless by dividing by the product of the

62 Boltzmann constant $\left(\mathrm{k}_{\mathrm{B}}=1.38 \times 10^{-23} \mathrm{~J} \mathrm{~K}^{-1}\right)$ and the absolute temperature $\left(\mathrm{T}_{\mathrm{K}}\right)$. 


\section{Cited Literature}

64 (S1) Hogg, R.; Healy, T. W.; Fuerstenau, D. W., Mutual coagulation of colloidal dispersions. 65 Trans. Faraday Soc. 1966, 62, 1638-1651

66 (S2) Gregory, J., Approximate expression for retarded van der Waals interaction. J. Colloid 67 Interface Sci. 1981, 83, 138-145.

68 (S3) Ruckenstein, E.; Prieve, D. C., Adsorption and desorption of particles and their

69 chromatographic separation. AIChE J. 1976, 22, 276-285.

70 (S4) van Oss, C.J. Interfacial Forces in Aqueous Media. Marcel Dekker (New York), 1994.

71 (S5) Oliveira, R. Understanding adhesion: a means for preventing fouling. Exp. Therm. Fluid

72 Sci. 1997, 14, 316-322.

73 


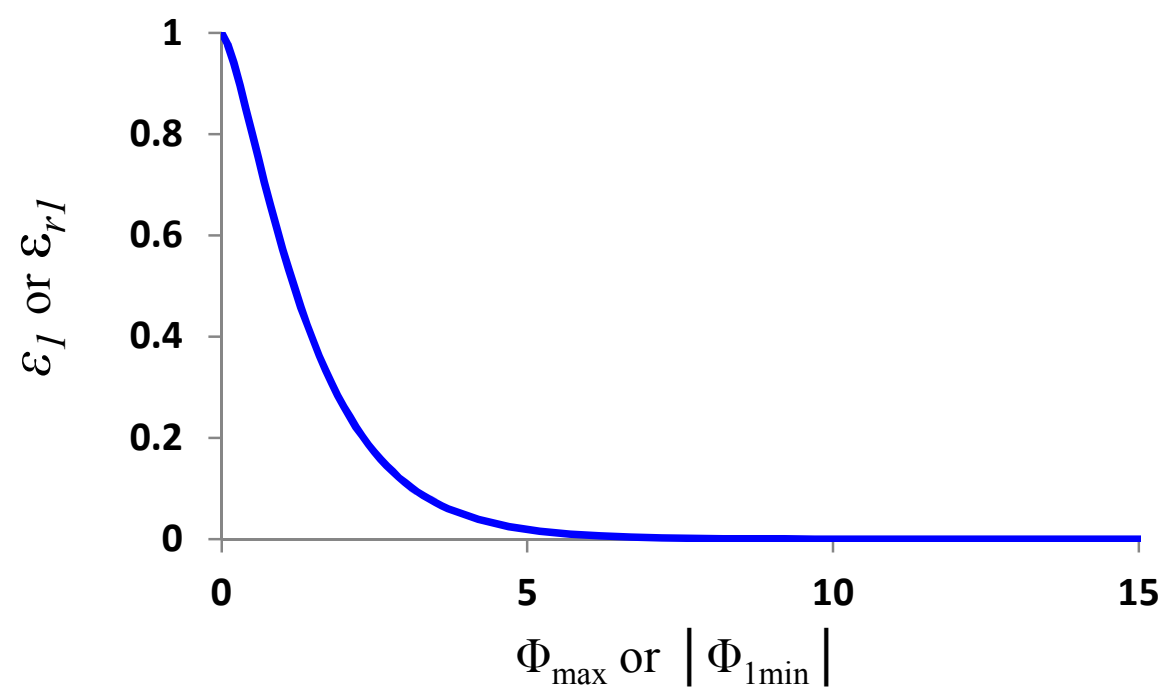

75 Figure S1. Plots of $\varepsilon_{1}$ as a function of $\Phi_{\max }$ when $\Phi_{2 \min }=0$ and $\Phi_{1 \min }=-\infty$ (unfavorable

76 electrostatic conditions), and $\varepsilon_{r 1}$ as a function of the magnitude of $\Phi_{1 \min }$ when $\Phi_{2 \min }=0$ and $77 \Phi_{\max }=0$ (favorable electrostatic conditions). 


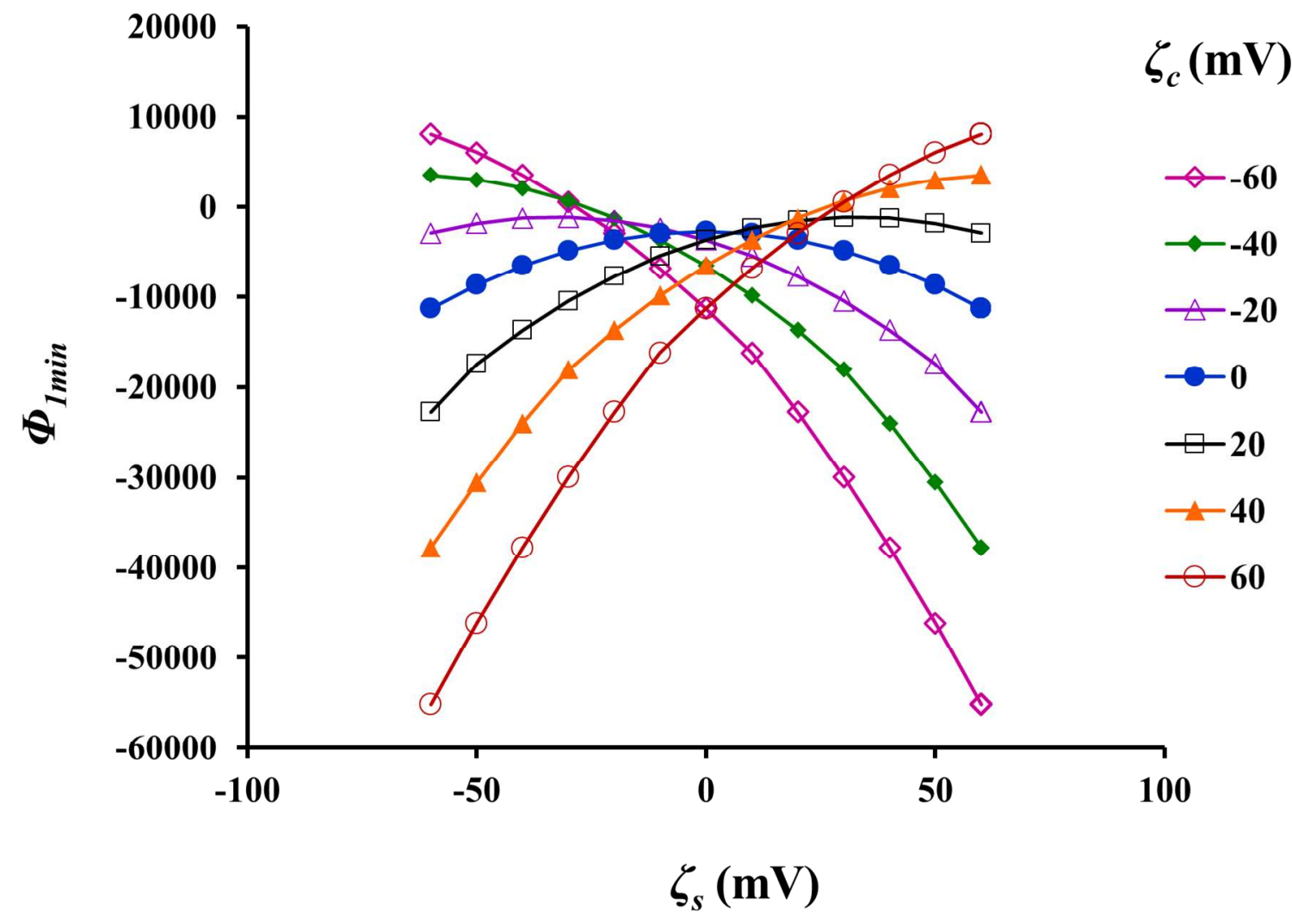

Figure S2. Plots of $\Phi_{1 \min }$ for a physically and chemically homogeneous oocyst and SWI when 81 the IS $=10 \mathrm{mM}$ and the zeta potential of the oocyst and the SWI were varied between -60 to 60 $82 \mathrm{mV}$. 